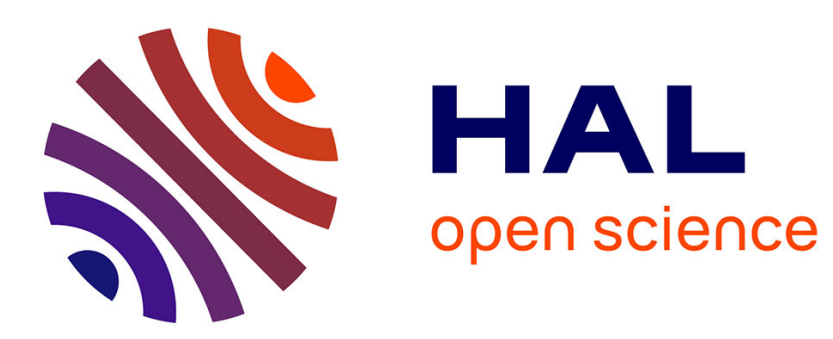

\title{
Identifying user experience dimensions for mobile incident reporting in urban contexts
}

Marco Winckler, Cédric Bach, Regina Bernhaupt

\section{To cite this version:}

Marco Winckler, Cédric Bach, Regina Bernhaupt. Identifying user experience dimensions for mobile incident reporting in urban contexts. IEEE Transactions on Professional Communication, 2013, vol. 56 ( $\mathrm{n}^{\circ} 2$ ), pp. 97-119. 10.1109/TPC.2013.2257212 . hal-01154282

\section{HAL Id: hal-01154282 \\ https://hal.science/hal-01154282}

Submitted on 21 May 2015

HAL is a multi-disciplinary open access archive for the deposit and dissemination of scientific research documents, whether they are published or not. The documents may come from teaching and research institutions in France or abroad, or from public or private research centers.
L'archive ouverte pluridisciplinaire HAL, est destinée au dépôt et à la diffusion de documents scientifiques de niveau recherche, publiés ou non, émanant des établissements d'enseignement et de recherche français ou étrangers, des laboratoires publics ou privés. 


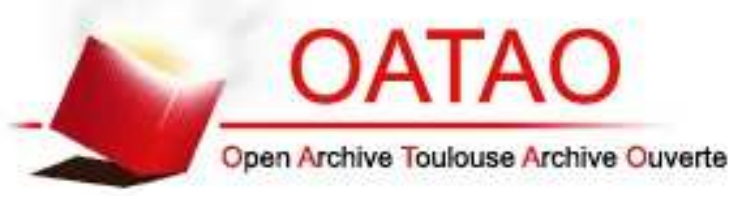

\section{Open Archive TOULOUSE Archive Ouverte (OATAO)}

OATAO is an open access repository that collects the work of Toulouse researchers and makes it freely available over the web where possible.

This is an author-deposited version published in : http://oatao.univ-toulouse.fr/ Eprints ID : 12465

To link to this article : DOI:10.1109/TPC.2013.2257212

URL : http://dx.doi.org/10.1109/TPC.2013.2257212

To cite this version : Winckler, Marco Antonio and Bach, Cédric and Bernhaupt, Regina Identifying user experience dimensions for mobile incident reporting in urban contexts. (2013) IEEE Transactions on Professional Communication, vol. 56 $\left(\mathrm{n}^{\circ} 2\right)$. pp. 97-119. ISSN 0361-1434

Any correspondance concerning this service should be sent to the repository administrator: staff-oatao@listes-diff.inp-toulouse.fr 


\title{
Identifying User Experience Dimensions for Mobile Incident Reporting in Urban Contexts
}

\author{
- Marco Winckler, Cedric Bach, and Regina Bernhaupt
}

\begin{abstract}
Research problem: Despite the increasing interests raised by incident reporting systems, it is still unclear what dimensions of user experience (UX) and other contextual factors should be taken into account for the various stages of declaring an incident using mobile-phone applications. Research questions: How do citizens perceive and describe urban incidents? What UX dimensions are important for reporting an incident with a mobile-phone application? What other (contextual) factors are important from the users' point of view when declaring incidents? Which of the UX dimensions and contextual factors are important when in the various phases during an incident declaration? Literature review: Overall, there is a lack of empirical research in the domain of incident reporting. In general, the UX dimensions-visual and aesthetic experience, emotion, stimulation, identification, meaning and value, and social relatedness/coexperience-are important when designing interactive systems. It also shows that incidents are related to the citizen's perception of the environment. Methodology: A triangulated method approach combining interviews, a survey of existing systems, and a model-based task analysis were applied. This allows us to present a generic task model for incident reporting with a detailed description of UX dimensions affected in the various subtasks. Results and conclusions: Our findings point out the effect of UX dimensions in the task engaged by users when reporting urban citizens. The overall UX is directly influenced by the perceived level of severity, inconvenience and involvement, the personal context, and the technological mobile context. We have found that while several UX dimensions are highly relevant, they are not equally distributed along the several subtasks that citizens engage when reporting incidents. This study shows that semistructured requirement interviews can provide information about UX dimensions and it highlights the importance of the identification of UX dimensions in early phases of the development process.
\end{abstract}

Index Terms-e-government, incident reporting, mobile services, service quality, smart phone, user experience (UX).

\section{INTRODUCTION}

In ncident reporting is a very well-known technique in safety-critical domains, such as air-traffic management [1] and health [2], [3], where specialized users are trained to provide detailed information about accidents or a deviation from current policies. In these domains, reporting an incident is part of the work routine. An incident report often features a document that focuses on objective facts rather than personal opinions. Reporting incidents is considered an important mean for monitoring the quality of the environment and enables authorities to promote safety and improve the technical systems (either in terms of design and/or working procedures).

In recent years, several governments have started to make use of information and communication technology to allow citizens to report urban incidents in their neighborhood (such as a broken street lamp or a street water leak) to the local

The authors are with the ICS-IRIT, Universite Paul Sabatier, Toulouse Cedex 31062, France (email: winckler@irit.fr). administration. In this context, citizens can use incident reporting tools as self-service applications [18], allowing the citizens to produce and consume services electronically without direct contact with the local administration. These applications are part of a variety of initiatives for promoting active participation of citizens in the actions of the government through the use of information and communication technology (e-government) [4], and mobile and wireless technology (m-government) [5], [6]. The state of Virginia (US) was a pioneer in deploying m-government applications, such as weather forecast, election monitoring and tourism information [7]. New applications, such as BlueTooth [8], use geolocation functions (GPS) embedded into cell phones to deliver personalized information to citizens (such as emergency phone calls and events taking place in the city). Although most m-government applications concern an urban environment (such as traffic jams, parking availability in town, and WiFi access), applications have been used even in rural areas [9].

Currently, many m-government services publish information through citizens' cell phones, but few services allow citizens to interact with the administration. For example, Fixmystreet allows users to report incidents in the cities that adopted 
this system [11]; however, the user interface provided is only available on web platforms and does not take into account the specifics of mobile technology.

Mobile technology offers many opportunities for m-government to obtain citizens' feedback about their environment. The latest generation of mobile devices includes touch interaction, global positioning systems (GPS), and camera, so that mobile phones (smart phones) provide users/citizens with the means to report incidents by specifying, for example, the location (such as selecting the location on a map), sending a precise location identification (such as using GPS), or simply providing a proof of the incident (such as taking a photo). However, mobile technology also imposes some constraints [10]. Due to the small screen size and low resolution, m-government solutions have to avoid the display of the same quantity of information compared to a standard computer. The same holds true for interaction resources (such as data inputs) which are also restricted.

The acceptance of m-government services is directly related to the ability of the application to address the users' needs [12], [13]. The issues of interface design are critical in the development of interactive systems, and usability of applications should be a central objective of conception [14]. A high-quality interface allows users to achieve their purpose (such as notification of an incident) in an efficient and satisfying way. Moreover, users might become dissatisfied and/or upset if they fail to achieve a goal. Thus, beyond usability, the overall (positive) user experience (UX) is important to make a service successful in terms of user takeup and frequency of usage. UX is a concept that goes beyond the pragmatic aspect of usability by taking into account dimensions such as emotion, aesthetics or visual appearance, identification, stimulation, meaning/value or even fun, enjoyment, pleasure, or flow [15].

For quite a while, it became clear that users do not only expect to receive information from the government, but citizens also expect to inform the government of their specific needs or experiences [16]. The willingness (and need) of direct and onsite citizen involvement is often highlighted during natural disasters and massive accidents [17]. Despite the fact that active use of the service is a key success factor, little is known about incident reporting systems by citizens in the field of m-government. So far, there have been no prior studies investigating what UX dimension should be taken into account when designing self-service systems for reporting incidents in urban contexts using mobile technology. Even less is known about how the UX with such systems might affect citizens' opinion about the quality of the service provided by the government.

The main goal of this work is to investigate which UX dimensions contribute to the overall user experience in the domain of incident reporting with mobile phone applications. This research was conducted within the project FEDER Ubiloop. Our working scenario is illustrated by Fig. 1 that presents how citizens might use diverse types of devices (mainly mobile phones) to report incidents such as potholes, missing road signs, graffiti, broken furniture in parks, and hornets. Ubiloop is proposed as a self-service system for mediating the communication between citizens and the administration. It presumes that incidents reported by citizens will prompt the city administration to those problems that are perceived as affecting their quality of life in the city. On one hand, the citizens are empowered with a system that will help them to autonomously perform an incident report, thus reducing bureaucracy. On the other hand, the city administration can have access to data provided by citizens, thus improving the detection of problems that would be difficult to identify otherwise.

In this context, the present study addresses the following research questions:

RQ1. How do citizens perceive and describe urban incidents as part of their perception of the quality of the environment?

RQ2. What dimensions of UX are important for reporting an incident with a mobile-phone application?

RQ3. What other (contextual) factors are important from a user's point of view when declaring incidents?

RQ4. Which of the UX dimensions and contextual factors is important when in the various phases during an incident declaration?

Since the context of incident reporting in urban contexts has sparsely been investigated from a human-computer interaction (HCI) or psychology perspective, it was important to first understand the context in which the mobile incident reporting application will be used and, second, to identify the relevant UX dimensions. In the next section, we present the state of the art on UX in general. Then, we present the methodological approach we have 
employed during our research, which encompassed the triangulation of three methods: two types of interviews with end users (semistructured requirement interview; scenario-based interview), a model-based task analysis, and a survey of existing systems. The section on result is structured following the typical task of declaring an incident: first, we present results on how people perceive the environment and what they perceive as incidents (semistructured requirement interview), then, the UX dimensions were identified based on the second interview (scenario-based interviews). To validate the findings, a model-based task analysis is used, identifying all possible tasks for an incident report. An ideal incident reporting system would support all of these tasks. This model-based task analysis was then compared with the results of a survey on incident reporting systems, showing to what extent current systems do support the general task. This general task model was then triangulated with the data from the interviews, identifying different UX dimensions for the various subtasks in the general model-based task description. This paper concludes with a discussion and future research section.

\section{LITERATURE REVIEW}

The main contribution of our work is on what user experience dimensions are important for incident reporting with mobile-phone applications. We are not aware of any work identifying UX dimensions for incident reporting; thus, a general overview on UX and the selection of UX dimensions for reporting incidents via mobile-phone applications is presented. The goal of this section is to revise the literature about UX dimensions and discuss in which extensions they are relevant to the design of incident reporting systems. Therefore, this section starts with an overview of the theoretical orientation, how literature was selected, followed by the definition of UX dimensions and the influence of the context.

Theoretical Orientation Incident reporting systems are related to several applications domains, including safety-critical systems, mobile technologies, and e-government. Despite the fact that vast literature in these domains exists, there is very little information about which UX dimensions should be taken into account when designing incident reporting systems. As far as incident reports systems are concerned, we assume their usage will be influenced by 1) the general UX when interacting with the mobile phone (as a product), but also by all experiences when interacting with the specific services and the service characteristics in 2) the specific usage context.

\section{Selection of Literature for the Review We have} started investigating publications in the field of HCI by looking for results of empirical studies with users using incident reporting systems and UX dimensions that should be taken into account when designing such applications. For that purpose, we have browsed digital libraries, such as ACM DL, Springer Link, and IEEE Xplore using the keywords user experience (UX), incident reporting systems, and mobile applications; selected articles should comply with (at least) one of the following criteria: to provide a definition on the topics covered by this paper, to illustrate existing applications in the domain, to identify problems that remain to be solved in the domain, and reporting empirical studies with citizens. We have found very few studies addressing specifically incident reporting systems. Conversely, we have selected many references that describe the importance of UX dimensions in the design of interactive systems. We also have selected references that describe contextual factors related to the application domain.

UX Dimensions An overall positive UX can be the key to the longer term acceptance and usage of a system [19]. UX can be defined as to go beyond usability, focusing on cognitive, sociocognitive, and affective aspects of the UX in their interaction with artifacts [20]. UX is commonly understood as being subjective, dynamic, and context dependent [21].

It is still controversial if UX is measurable [22]. This work assumes that it is possible to measure a set of dimensions that contribute to the overall UX. What is important to note is that limited usability must not lead to a bad UX, but on the contrary, can lead to a positive UX, while good usability does not necessarily lead to a positive overall UX. This has been shown, for example, in the area of interactive TV [23].

The literature in HCI describes a broad variety of dimensions that are associated with UX. To understand the most important UX dimensions, we did a literature review on all available publications on UX starting in the early 1990s, with a focus on journals and publications in the field of HCI. Based on an assembly of 247 articles, we identified a set of UX dimensions that are central for interactive systems. Table I shows the six most commonly described UX dimensions in HCI literature. Due 
Urban incidents

Citizens
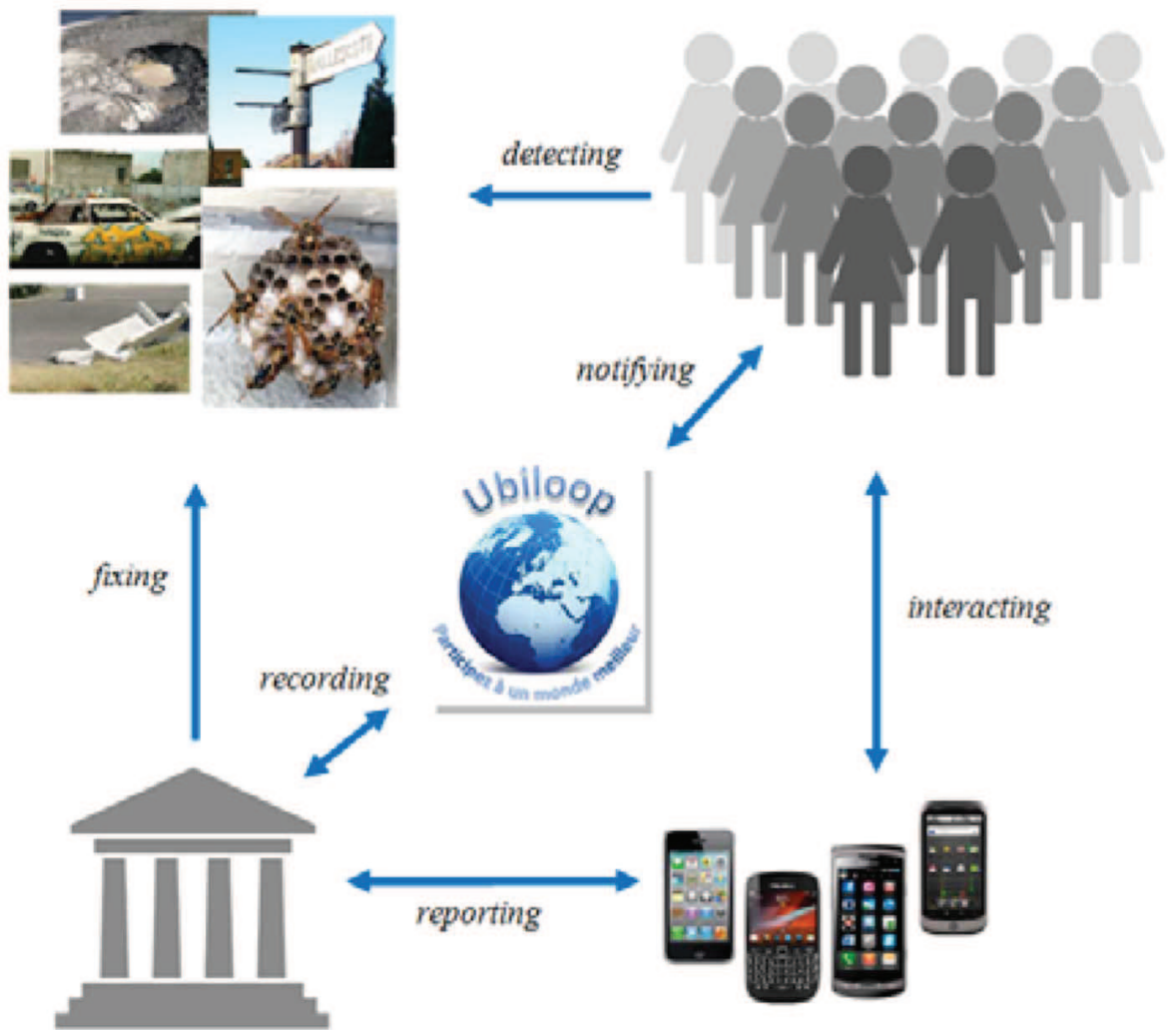

\section{City Adminis tration}

Mobile technology

Fig. 1. Overview of incident reporting: users report incidents like potholes, tagging, obstacles, or broken street lamps to the local government using mobile-phone applications.

to space constraints, the table only indicates a selection of the most important references.

The dimension visual and aesthetic experience refers to the pleasure that people gain from sensory perceptions, how beautiful something is perceived [24]. It includes beauty [25] and refers to classic aesthetics characteristics like clarity and symmetry [25], [26]. Overall, it is about how aesthetically pleasing and sensually satisfying an interaction is [27]. It has been shown that attractiveness and aesthetics do have a significant influence on the perceived usability of a system [28], [29].

Emotion has been identified as a key dimension of UX [25]. For Desmet and Hekkert [30], the emotional experience is one of the three main dimensions contributing to product experience, including feelings and emotions elicited. Alben [28] addresses the dimension emotion as an outcome for user interaction. Mahlke and Thüring [31] state that affect and emotion are considered as important parts of the UX with interactive systems before, during, and after interacting with the system.
Hassenzahl [25] describes stimulation as a hedonic attribute of a product, which can lead to new impressions, opportunities and insights. Sheldon et al. [32] state the need for pleasurable stimulation, focusing more on joyful aspects of the interaction. Hedonic experiences were subsumed by Karapanos et al. [33] under the term "innovativeness" to describe the ability of a product to excite the user through its novelty.

For Hassenzahl [34], the identification dimension addresses the human need to express one's self through objects. This self-presentational function of products is entirely social; as individuals want to be seen in specific ways by relevant others. Thus, using or owning a specific product is a way to reach a desired self-presentation. Identification can be seen as self-expression through an object to communicate identity. Jääskö and Mattelmäki [35] define user personality as part of user experience in sociocultural contexts, including the self-image, attitudes, values, lifestyle, and previous experiences. 
Meaning and value refer to "Ideo pleasure" [36], indicating values the product can satisfy. This means that products are sometimes chosen because they reflect or represent values that are important to the person. Desmet and Hekkert [24] refer to two aspects of meaning: the experience of meaning and the meaning attached to a product.

The construct of social relatedness/coexperience as a UX dimension is addressed by Gaver and Martin [37] under the term of intimacy which is used to refer to nonverbal, inexplicit forms of communication. Jordan [36] describes the construct of sociopleasure as something that deals with interaction with others. Products that facilitate communication as well as those that serve as conversation pieces contribute to sociopleasure.

Mobile service UX has been defined as the combination of dimensions of service experience and UX [38]. Service experience is affected by dimensions, such as perishability, intangibility, and the self-service nature of the services itself [39]. There are a variety of elements that should be taken into account for any type of mobile-based services, including the coherence of the service integration, social navigation and interaction, the ability to dynamically change services, the intangibility of the service, and the availability of multiple interaction styles [40].

In this paper, we investigate how these UX dimensions are reported by users during semidirected requirements interviews and in which extensions they are related to tasks that users engage in when reporting incidents.

Influence of the Context Before designing and developing an incident reporting system, it is important to understand how people perceive and act on the environment. Currently, the main mechanisms on how individuals act in their environment are poorly understood in the field of environmental psychology [41] and unfamiliar to the HCI domain. Nonetheless, it seems important to know: (1) how individuals perceive their environment, (2) how they discover incidents, and (3) how they transfer this knowledge to self-service systems. Two concepts are important to understand how people perceive their environment: place identity and amenity. Place identity [42] refers to the cognitive aspects related to the perception of the environment, including one's attitudes, feelings, ideas, memories, personal values, and preferences toward the whole range and all types of physical settings. These aspects of place identity allow people to understand the environment they live in and their overall experience. In this way, one can consider place identity as a structure of the self-identity, which means situated and self-centered. Thus, the same physical environment can be perceived differently by individuals. For example, a handrail can be perceived as an aid for elderly people and as an object to play with for kids.

The concept of amenity refers to the ability of spaces to evoke emotional responses, such as attractiveness and desirability. Amenity refers to any benefits of a property, especially those that affect attractiveness or value of places. Amenities include facilities, such as restaurants, parks, swimming pools, theaters, children's playgrounds, and bicycles paths. Amenities also include pleasant architecture, nearby activities, good schools, or a low crime rate, all of which add to the desirability of place and property. The concept of amenity explains how environmental qualities can have an impact on the hedonic and social perception of environment.

The identification or perception of an incident is related to a mental contradiction between an expected state of the environment (influenced by the place identity of a person and the amenities given in that environment) and the real state of this environment. When this contradiction is too high, people feel the need to report this contradiction or correct it.

For Moles and Rohmer [43], the main role of the urban environment is to act as a mediator between individuals and the society. Such mediators exist on different levels ranging from a macro to a micro level. At the macro level, the role of the urban environment includes building public transportation or the global management of the city. Individuals typically do not have a lot of influence on the macro level. On the micro level, the urban environment refers to events and objects that individuals interact with in their daily actions (like taking a bus or enjoying a park). Thus, the role of a designer of any incident reporting system would be to improve the communication between the individual (and his or her daily experiences on the micro level of the urban environment) and the local administration or government (on the macro level of the urban environment).

\section{MetHodologY}

The goal of our research is to understand what UX dimensions contribute to the overall UX in the domain of incident reporting with mobile-phone 
applications. The following sections explain how we attempted to reach this goal. It first explains our choice of a research methodology. After explaining the choice of a research methodology, we separately describe the participants, processes, and data-analysis techniques for each of the methods we used.

Choice of Research Methodology To answer the research questions, we have been triangulating and applying three methods: (1) interviews, (2) a survey of existing systems, and (3) a model-based task analysis. The methods were applied in the following three steps:

Step 1) To understand how citizens perceive incidents (RQ1), we have been performing a semistructured interview, identifying requirements for mobile applications for incident declaration.

Step 2) To understand what UX dimensions are important (RQ2) and what other dimensions can be influencing the design and development (RQ3), we:

(a) identified scenarios of typical incidents in the semistructured requirement interviews;

(b) we completed and extended the scenarios and the scenario description by comparing them with the results of a survey on existing systems;

(c) we then conducted the scenario-based interviews.

Step 3) To identify what UX dimensions are important during an incident declaration (RQ4):

(a) a model-based task analysis was performed (based on the survey of existing systems)

(b) the UX dimensions and (contextual) factors were associated with the subtasks in the model-based task description.

Semistructured Requirement Interview In order to understand users' requirements for incident reporting systems, we have conducted a semistructured requirement interview.

Participants All participants were French native speakers. Their education level ranged from high school to obtaining a Ph.D. They lived in France in the Toulouse metropolitan area for at least two years and up to 40 years $(M=13, S D=10)$.
TABLE I

SUMMARY OF LITERATURE REVIEW OF UX DIMENSIONS

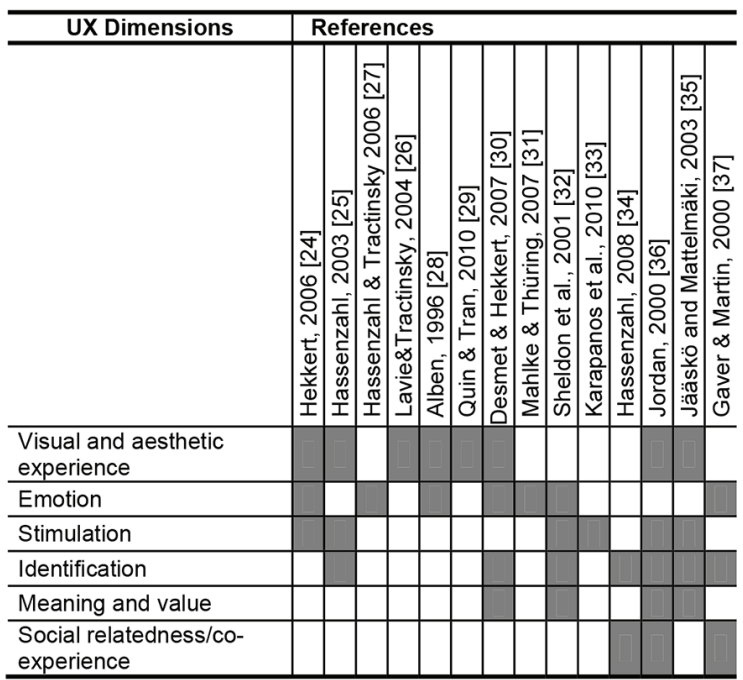

Note: means UX dimension reported by the respective authors

For the semistructured requirement interview, we had nine participants (labeled in the following P1 to P9) six males and three females $(M=40$ years old, $S D=15$ ). Participants were selected from a neighborhood association that had been previously identified as a pilot test population for the Ubiloop project. Our goal when recruiting participants, who are already actively engage in local communities, was to have participants who would be very likely to report incidents and who would be ready to actively act when detecting an incident. In order to gain better insight on necessary requirements for smart-phone applications to report incidents, we selected participants that were knowledgeable in terms of smart-phone usage. All participants owned at least one smart phone (and up to three mobile phones). Phones were used to make phone calls $(n=9)$, send short text messages $(n=8)$, receive and send email $(n=5)$, access the internet via the phone $(n=6)$, make photos $(n=8)$ or videos $(n=$ $3)$, and use the GPS $(n=5)$.

How Data Were Collected. At first, participants were informed about the goal of the interview: to explore the utility of smart-phone applications for reporting changes or degradations in the quality of the environment. Then, they were prompted to report about:

(a) How they perceive places and their environment; such as to tell dimensions they consider important for the quality of their environment (either their neighborhood or working place). 
Negative experiences in terms of environmental quality; such as to tell about events they have in their neighborhood or working place.

Personal involvement with problems; such as to identify who they think should be in charge of solving problems in their neighborhood: themselves (personal level) or the local government (societal level).

Preferred system design; such as to tell how they would like to report degradations of the environment (such as incidents) and what kind of technology should be used (for example, web service on PC or smart phones).

(b) UX dimensions they think are important; such as to name elements that are important for a good experience or a good quality of service.

Identification of Scenarios To analyze the actual support provided by existing applications, we conducted an analysis of existing services for incident reporting in urban contexts. This survey focused on the front office (such as reporter tools) and not on the back office (such as officer tools). Applications for incident reporting were first identified from the set of tools ranked by web search engines (such as google.com). Then, only those that were available for remote testing were selected for further analysis. Fifteen applications were selected covering international and national incident reporting services (covering the US, Canada, UK, the Netherlands, Australia, New Zealand, Norway, South Korea, Spain, and India) and eight city services (New York, Vienna, Copenhagen, Lisbon, and four French towns: Paris, Pouancé, Merignac, and Athis-Mons). Most applications are accessible from the website of city administrations.

These 23 applications included different technological platforms resulting in eight services that are available only on the web (such as those that can be used only on standard computers), three services that are optimized for webmobile (such as those that can be used on smart phones and standard computers), ten applications that are delivered through the web but also provided as an embedded smart-phone application, and two services that are available as embedded smart-phone apps only. In a second step, we excluded all web applications and focused only on those that are available on mobile platforms.

The remaining 12 applications were then compared accordingly to their task support for reporting incidents as described in Table II.
Despite the fact that these applications address the same problem of reporting incidents in an urban context using mobile technology, the scenarios implemented are different. For example, while in some systems the identification of the user is mandatory, others accept anonymous reports; in some systems, users can chose how to provide the location (such as an address or GPS coordinate). Other solutions only offer a simple text field for entering an address.

As far as the main task "detect incident" is of concern, four applications provide some support to help users recognize what type of problem would be an incident and the other four applications provide a mechanism for helping users identify how to solve the incident. None of the tools surveyed explicitly motivates users to report incidents.

The task "submit an incident" is supported by different scenarios but there is some consensus on subtasks such as "provide a description" using either text or a picture and "to locate the incident" by pinpointing it on a map. Other subtasks, such as select incident category, record when the incident is reported and provided personal coordinates (available in 11 of the 12 applications analyzed). To rate an incident in terms of severity is only possible in two applications and only one considers potential danger. While textual descriptions and pictures are common, none of the applications considers an alternative service, allowing the user to call a hotline, which would be effective for blind users for instance.

The use of interactive maps where users can pinpoint the incident is supported by all applications analyzed. GPS coordinates are supported by nine applications, four of them allow users to provide an address; another three allow users to use landmarks to locate an incident.

Most of the applications $(n=11)$ automatically collect the data/time when an incident is reported. Only one lets users provide the time when the incident occurred. All applications provide either support for users to share reports and/or to see reports from other users, but only four applications allow users to subscribe for the outcome or result associated with the incident they have reported. The presence of specific features does not necessarily add value to the system; in some cases, it might be the opposite, as the absence of unnecessary features might create a feeling of efficiency.

Based on this analysis and the results of the requirements interviews, we came up with seven 
scenarios that cover all identified aspects and subtasks of an incident declaration. They were used as input in the scenario-based interviews and are presented in the following section.

\section{Conducting Scenario-based Interviews For} the scenario-based interview, we invited nine participants (labeled P10 to P18 in results section), six males and three females $(M=27$ years old; $S D=6$ ). These participants represented a younger population compared to the participants from the first interview. Participants had a broad knowledge on various forms of information and communication technologies, using mobile phones and internet frequently. All nine participants stated they use their smart phones for calls and sending text messages, eight use it for mail and accessing internet via the smart phone, seven use it for making photos/videos and seven use the GPS function. However none of the 18 participants had used an application to report incidents using a smart phone. All participants gave written consent for participating in this study and our institution research ethics committee deemed the research "exempt."

For this interview, participants were asked to consider the seven scenarios identified earlier. Participants were introduced to each scenario and then asked to explain how they would envisage reporting the incident using their smart phones. The scenarios were chosen to represent the most common incidents in the area of Toulouse, represented incidents identified by users in the requirement interviews, and should reflect the most frequent types of incidents supported by existing systems. Moreover, each scenario was designed to highlight a specific context of use. The incidents explored in the scenarios include:

(1) Broken street lamp. This incident was chosen to explore situations that would be difficult to illustrate with a picture. Broken street lamps are often noticed during the night which makes photos almost impossible as many smart phones do not have a flash nor do they cover long distances. The scenario provides some geographic information to prompt if participants would use photos when reporting the incident.

(2) Pothole. The pothole incident was designed to investigate users' personal involvement. It describes people riding a bicycle over a pothole and then feeling backpain afterwards. This scenario is aimed to explore emotions and social behavior triggered by (negative) emotional experiences with incidents.

(3) Missing road sign. The scenario of a missing road sign takes into account possible limitations for using a smart phone to report an incident when people are in movement, for example, driving a car. This scenario explores time/place aspects of incident reporting.

(4) Bulky waste. In Toulouse, waste removal is performed by two different services: garbage trucks regularly collect any waste that fits into the standard waste containers; however to remove bulky waste, people need to call the local administration for booking a larger truck; otherwise, the waste will remain in place, causing a nuisance. This scenario explores how (active) usage of services can prevent incidents, what knowledge people have about local administration procedures (such as whom to call), and people's previous experiences with local administration.

(5) Hornet's nest. This scenario depicts a hornet nest close to a playground with some hornets flying around people. It is aimed to explore the influence of perceived danger on the incident reporting.

(6) Tag/graffiti. In this scenario the participant is told to be going to an appointment when he notices some fresh graffiti next to his car; participants promptly report this incident even if they are in a rush. This scenario is aimed to explore the perception of the level of nuisance and priority, need for immediate action, and feeling of duty toward society.

(7) Broken bench in a park. This scenario explores difficulties for locating precise incidents. It also prompts people to get involved with ( $a$ priori) minor incidents.

All sessions were recorded and then transcribed by a French native speaker. The transcriptions were analyzed accordingly to the Grounded Theory Approach [44], [45]. A corpus of 92,240 words was analyzed and coded accordingly to 11 classes/codes with 1125 segments of text. Every segment of text was interpreted accordingly to the context given in the scenario; for example, when users expressed a feeling of relief after reporting an incident, the segment was coded in the class emotions. In order to reduce the impact of subjective interpretation, we used the set definitions presented in the state of the art. Moreover, the coding was cross-checked by two independent reviewers with strong backgrounds (Ph.D.) in HCI. The 11 classes and codes refers to the six UX dimensions (including 
TABLE II

TAsks Supported by 12 EXISTING APPLICATIONS FOR Reporting InCIDENTS IN URBAn ConteXT

\begin{tabular}{|c|c|c|c|c|c|c|c|c|c|c|c|c|c|c|c|}
\hline \multicolumn{4}{|c|}{ Tasks for reporting an incident } & \multicolumn{12}{|c|}{ Existing mobile applications } \\
\hline & & & & 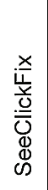 & 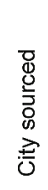 & 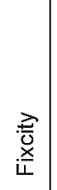 & 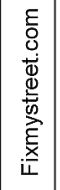 & 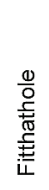 & 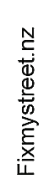 & 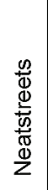 & $\begin{array}{l}\frac{t}{\overline{0}} \\
\frac{0}{0} \\
\frac{0}{0} \\
\frac{d}{0} \\
\frac{0}{0} \\
>\end{array}$ & 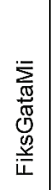 & 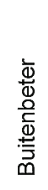 & 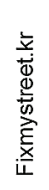 & 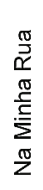 \\
\hline \multirow{3}{*}{ Detect incident } & \multicolumn{3}{|c|}{ Recognize incident } & & & & & & & & & & & & \\
\hline & \multirow{2}{*}{\multicolumn{3}{|c|}{$\begin{array}{l}\text { Identify who should solve the incident } \\
\text { Decide to report incident }\end{array}$}} & & & & & & & & & & & & \\
\hline & & & & & & & & & & & & & & & \\
\hline \multirow{13}{*}{ Submit an incident } & \multirow{5}{*}{ Describe the incident } & \multirow{3}{*}{$\begin{array}{l}\text { Select incident categor } \\
\text { Rate the incident }\end{array}$} & & & & & & & & & & & & & \\
\hline & & & Potential danger & & & & & & & & & & & & \\
\hline & & & \begin{tabular}{|l|} 
Inconvenience \\
\end{tabular} & & & & & & & & & & & & \\
\hline & & \multirow{2}{*}{ Provide a description } & \begin{tabular}{|l} 
Text \\
Picture
\end{tabular} & & & & & & & & & & & & \\
\hline & & & \begin{tabular}{|l} 
Call hotline \\
\end{tabular} & & & & & & & & & & & & \\
\hline & \multirow{4}{*}{ Locate the incident } & \multicolumn{2}{|l|}{ Provide address } & & & & & & & & & & & & \\
\hline & & \multirow{2}{*}{\multicolumn{2}{|c|}{$\begin{array}{l}\text { Pinpoint on a map } \\
\text { Use landmarks }\end{array}$}} & & & & & & & & & & & & \\
\hline & & & & & & & & & & & & & & & \\
\hline & & \multicolumn{2}{|l|}{ GPS coordinates } & & & & & & & & & & & & \\
\hline & \multirow{2}{*}{ Inform time of the incident } & \multicolumn{2}{|c|}{ Tell when incident occurs } & & & & & & & & & & & & \\
\hline & & \multirow{2}{*}{\multicolumn{2}{|c|}{ Record when the incident is reported }} & & & & & & & & & & & & \\
\hline & \multirow{2}{*}{ Provide user identification } & \multirow{2}{*}{\multicolumn{2}{|c|}{$\begin{array}{l}\text { Collect user ID from the system } \\
\text { Provide personal coordinates }\end{array}$}} & & & & & & & & & & & & \\
\hline & & & & & & & & & & & & & & & \\
\hline \multirow{3}{*}{ Follow up the incident } & \multicolumn{3}{|l|}{ Subscribe for notification } & & & & & & & & & & & & \\
\hline & \multirow{2}{*}{\multicolumn{3}{|c|}{$\begin{array}{l}\text { Share reports } \\
\text { See someone else reports }\end{array}$}} & & & & & & & & & & & & \\
\hline & & & & & & & & & & & & & & & \\
\hline
\end{tabular}

Note: means task is supported.

visual and aesthetic experience, emotions, stimulation, identification, meaning and value, and social relatedness/coexperience) plus contextual dimensions including user motivation (to report the incident), severity, (level of inconvenience, diversity of technical platforms, and communication style. The coding was supported by the MaxQDA 10 software [48].

Model-Based Task Analysis Typical user tasks for reporting incidents were analyzed and described using a model-based notation [47]. Task analysis is widely recognized as one fundamental way to focus on specific user needs and to improve the general understanding of how users may interact with a user interface to accomplish a given goal when using an interactive system [46]. A task model is a generalization of alternative solutions for achieving a goal-in our case, to report an incident. Each alternative solution is specifically addressed by a scenario. By modeling the tasks of reporting an incident, it is possible to have an abstraction of contextual alternatives, which is required for determining optional/mandatory tasks, inner dependencies between tasks, as well as pre and postconditions associated with task execution.

\section{RESULTS}

This section reports the results of the study. It integrates the results of the different parts of the study to provide cohesive answers to each research question. The section concludes by presenting a task model emerging from these results.

Results for Research Question 1 How do citizens perceive and describe urban incidents as part of their perception of the quality of the environment?

We found out that the starting point for any incident report relies on user's skills to detect the incident, which can be refined as being able (a) to identify an event that could be perceived as a problem or nuisance, (b) to detect an event that could prevent the occurrence of a likely problem, and (c) to envisage something worth reporting that could improve the quality of the environment and/or its management. For example: Participant 11 (in the future, we refer to participants as PXX, where $\mathrm{P}$ indicates participant and $\mathrm{XX}$ indicates their identification number) commented on the scenario of the pothole (a) “... this happened to me. I was driving with my bike on a pothole and it really damaged both of the wheels. At this occasion I really wanted to report the incident." P16: (b) "... I would be willing to spend more time explaining how to prevent that incident than would do for reporting just a minor incident [afterwards]." P7: (c) 
TABLE III

Synthesis OF InTERVIEws FocUSING ON UX DIMENSIONS THEIR CORRESPONDENCE WiTH TASKS AND IMPLICATIONS FOR THE DESIGN OF InCIDENT REPORTING SYSTEMS

\begin{tabular}{|c|c|c|c|c|c|}
\hline UX Dimensions & $\begin{array}{l}\text { Users } \\
\text { reporting the } \\
\text { dimension in } \\
\text { requirement } \\
\text { interviews } \\
\text { (population } \\
N=9 \text { ) }\end{array}$ & $\begin{array}{l}\text { Users } \\
\text { reporting } \\
\text { the } \\
\text { dimension } \\
\text { in scenario- } \\
\text { based } \\
\text { interviews } \\
\text { (population } \\
N=9 \text { ) }\end{array}$ & $\begin{array}{c}\text { Total of } \\
\text { segments } \\
\text { (requirement } \\
\text { interviews + } \\
\text { scenario- } \\
\text { based } \\
\text { interview) }\end{array}$ & User tasks & Implications for design of incident reporting systems \\
\hline \multirow{2}{*}{$\begin{array}{l}\text { Visual and } \\
\text { aesthetic } \\
\text { experience } \\
{[\mathrm{AX}]}\end{array}$} & \multirow[t]{2}{*}{6} & \multirow[t]{2}{*}{6} & \multirow[t]{2}{*}{$\begin{array}{c}21 \\
(4,2 \%)\end{array}$} & $\cdot$ & $\begin{array}{l}\text { All users express their preferences to applications for incident reporting, mainly } \\
\text { for aesthetics reasons. So, design options should be generally supported by a } \\
\text { smart-phone applications dedicated to incident reporting rather than a web } \\
\text { application running on mobile phone's browser. However, users wish to have a } \\
\text { website on a larger PC display to see a map of all reports in their neighborhood. }\end{array}$ \\
\hline & & & & $\begin{array}{l}\text { [Provide a } \\
\text { picture }{ }^{\prime} \\
\text { video] }\end{array}$ & $\begin{array}{l}\text { Users consider good pictures as more valuable and significant for incident } \\
\text { reporting. So, the service should provide guidance to take pictures with a good } \\
\text { visual quality (e.g., through photography tutorial). }\end{array}$ \\
\hline \multirow{4}{*}{ Emotions [EM] } & \multirow{4}{*}{9} & \multirow{4}{*}{6} & \multirow[t]{4}{*}{$\begin{array}{c}61 \\
(12,1 \%)\end{array}$} & 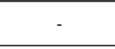 & $\begin{array}{l}\text { Declare incident helps users to improve the quality of their environment. This } \\
\text { contributes to an overall positive emotional state. }\end{array}$ \\
\hline & & & & $\begin{array}{l}\text { [Select } \\
\text { incident } \\
\text { category] }\end{array}$ & $\begin{array}{l}\text { Some types of incident would generate negative emotional responses. For } \\
\text { example "dangerous" animals as hornets, rats, or snakes are a source of phobia. } \\
\text { The system should help users to regain their calm by reporting the incident and by } \\
\text { providing safety instructions. }\end{array}$ \\
\hline & & & & $\begin{array}{l}\text { [Rate } \\
\text { potential } \\
\text { danger] }\end{array}$ & $\begin{array}{l}\text { Rate the perceived danger of an incident is a mean to express a negative } \\
\text { emotion, especially when users had been involved in the incident (see case study } \\
\text { of the pothole). It'th helpful to regain calm and rationality. So, the design option } \\
\text { should provide sliders to rate incidents. }\end{array}$ \\
\hline & & & & $\cdot$ & $\begin{array}{l}\text { Some users declare that they would be proud to help local administration to } \\
\text { improve the environment quality. Design options would be to support collective IR } \\
\text { as events / games (i.e., organized by local administration) in order to improve the } \\
\text { emotional involvement with the service. }\end{array}$ \\
\hline \multirow{3}{*}{ Stimulation [ST] } & \multirow{3}{*}{9} & \multirow{3}{*}{2} & \multirow[t]{3}{*}{$\begin{array}{c}29 \\
(5,7 \%)\end{array}$} & $\begin{array}{l}\text { [Submit an } \\
\text { incident } \\
\text { report] }\end{array}$ & $\begin{array}{l}\text { Smart-phone applications that provide an easy and fast way to submit a list of } \\
\text { incidents also stimulate users to submit incident. Design options should globally } \\
\text { favor efficient applications integration in the smart-phones' operational system. }\end{array}$ \\
\hline & & & & $\begin{array}{l}\text { [Select } \\
\text { incident } \\
\text { category] }\end{array}$ & $\begin{array}{l}\text { Incident categories are a good mean to prompt users to recognize then declare } \\
\text { different types of incidents. Nevertheless, incident categories should be short (i.e., } \\
5 \text { items through } 3 \text { levels) to avoid short-terms memory workload. }\end{array}$ \\
\hline & & & & $\begin{array}{l}\text { [See } \\
\text { someone's' } \\
\text { else reports] }\end{array}$ & $\begin{array}{l}\text { Look at other reports is a good mean to share different users' point of views and } \\
\text { also to recognize problems encountered by different citizens. Users prefer to } \\
\text { make this activity at home on a website. Design options should provide interactive } \\
\text { maps, including filters, available on website. }\end{array}$ \\
\hline Identification [ID] & 9 & 9 & $\begin{array}{c}150 \\
(29,6) \%\end{array}$ & $\begin{array}{l}\text { [Decide to } \\
\text { report the } \\
\text { incident] }\end{array}$ & $\begin{array}{l}\text { Decision to report is a consequence of both user's personality (e.g., citizens' duty) } \\
\text { and the mean to do it. } \\
\text { In terms of design implications, the users should have a mean to instantly report } \\
\text { an incident when they perceive it. For now, this mean should be his/her smart } \\
\text { phone including a dedicated app. }\end{array}$ \\
\hline \multirow{7}{*}{$\begin{array}{l}\text { Meaning and } \\
\text { values [MV] }\end{array}$} & \multirow{7}{*}{9} & \multirow{7}{*}{9} & \multirow[t]{7}{*}{$\begin{array}{c}110 \\
(21,7) \%\end{array}$} & $\begin{array}{l}\text { [ldentify who } \\
\text { should solve } \\
\text { the incident] }\end{array}$ & $\begin{array}{l}\text { The users expect to know the effective means, benevolence, and aims of the e- } \\
\text { services and generally how the service can work. This is important because it's a } \\
\text { precondition (for users) to use and be confident with the system. } \\
\text { In terms of design solutions, this should lead to a video and/or a webpage } \\
\text { describing the service intentions, means, policies, and workflows. }\end{array}$ \\
\hline & & & & $\begin{array}{l}\text { [Provide a } \\
\text { description] }\end{array}$ & $\begin{array}{l}\text { Users involved in incident declaration would like to provide valuable reports. So, } \\
\text { according to the incident type, users would like to provide (at least) the mandatory } \\
\text { data. } \\
\text { A design solution should be to provide a kind of template and/or a tutorial } \\
\text { explaining how to provide efficient incident description. For this point, the } \\
\text { guidance of users is important, especially for incidents that are potentially } \\
\text { dangerous. }\end{array}$ \\
\hline & & & & $\begin{array}{l}\text { [Locate the } \\
\text { incident] }\end{array}$ & $\begin{array}{l}\text { Location of incident is a mandatory issue for IR. So users would like to provide a } \\
\text { good location of the incident. Most of them suggest using cardinal coordinates } \\
\text { (i.e., with the use of GPS). However, some users would also like to keep control } \\
\text { on the transfer of these coordinates. Indeed, some users identify cardinal } \\
\text { coordinates as private data and would like to transfer them only after an explicit } \\
\text { action. } \\
\text { So in terms of design solution, the user should allow (or avoid) automatic location, } \\
\text { for example in a "preferences" menu of the app. }\end{array}$ \\
\hline & & & & $\begin{array}{l}\text { [Provide user } \\
\text { ID] }\end{array}$ & $\begin{array}{l}\text { Users consider their identification as a credibility cue of their reports. They also } \\
\text { consider identification as a mean to prevent the service from fake reports. } \\
\text { Neverthelesss, some users expect to have an option of automatic identification, in } \\
\text { the purpose of effectiveness, but another part of users would like to transfer their } \\
\text { identification after an explicit action. } \\
\text { So, as location, a design option should propose an option between automatic and } \\
\text { explicit identification (e.g., in a preferences menu). }\end{array}$ \\
\hline & & & & $\begin{array}{l}\text { [Subscribe for } \\
\text { notification] }\end{array}$ & $\begin{array}{l}\text { Notifications are a cue of the local administration capability to manage/solve IR. } \\
\text { Depending on the incident type and the level of user involvement with the }\end{array}$ \\
\hline & & & & & $\begin{array}{l}\text { incident, users would like to be informed of IR evolution. } \\
\text { A design option, during the IR procedure, should propose to users to freely } \\
\text { subscribe for notifications. }\end{array}$ \\
\hline & & & & $\begin{array}{l}\text { [Share } \\
\text { reports] }\end{array}$ & $\begin{array}{l}\text { Users consider the different signs of the service activities as cues of value and } \\
\text { credibility of the service. } \\
\text { In terms of design option, a mean to share reports with local admin /citizens would } \\
\text { be a mean to appreciate the overall activity of local admin in order to solve } \\
\text { incidents. }\end{array}$ \\
\hline \multirow{5}{*}{$\begin{array}{l}\text { Social relatedness } \\
\text { Co-experience } \\
\text { [CX] }\end{array}$} & \multirow{5}{*}{9} & \multirow{5}{*}{9} & \multirow[t]{5}{*}{$\begin{array}{c}135 \\
(26,7) \%\end{array}$} & $\begin{array}{l}\text { [ldentify who } \\
\text { should solve } \\
\text { the incident] }\end{array}$ & $\begin{array}{l}\text { Users will share information only if they estimate that information would be taken } \\
\text { into account by at least one service. So, in order to prompt users to report } \\
\text { incidents, it is important to indicate which service is in charge to take into account } \\
\text { which type incident (e.g., in the notifications, on the website describing the } \\
\text { service workflow). }\end{array}$ \\
\hline & & & & $\begin{array}{l}\text { [Provide a } \\
\text { picture/ video] }\end{array}$ & $\begin{array}{l}\text { Pictures or videos are a good mean for users to explain to someone else the } \\
\text { incident and its context. The service should help users to take an efficient picture } \\
\text { of an incident, for example through a tutorial. }\end{array}$ \\
\hline & & & & $\begin{array}{l}\text { [Call a hot } \\
\text { line] }\end{array}$ & $\begin{array}{l}\text { Some users would share their experience of an incident directly by phone, } \\
\text { especially with dangerous ones (e.g., Hornet nest). Furthermore, a phone call is a } \\
\text { direct mean to ensure users that the local administration shares the same } \\
\text { comprehension of the incident. To do this, the app should provide a mean to call a } \\
\text { hotline, according to the incident type. }\end{array}$ \\
\hline & & & & $\begin{array}{l}\text { [Subscribe for } \\
\text { notification] }\end{array}$ & $\begin{array}{l}\text { Users don't expect automatic responses. The service should provide a } \\
\text { reformulation of incident report by human agents. }\end{array}$ \\
\hline & & & & $\begin{array}{l}\text { [Share } \\
\text { reports] }\end{array}$ & $\begin{array}{l}\text { Sharing information is important to build and keep a community around incident } \\
\text { reporting activities (i.e., between administration and citizens). Design options } \\
\text { should provide interactive maps with filters to show/locate the different incidents. } \\
\text { Subscription to RSS flow would be also a solution to share reports with other } \\
\text { citizizens. These kinds of activities should be supported mainly by dedicated } \\
\text { websites at home. }\end{array}$ \\
\hline
\end{tabular}


"With this e-service you could make a request to add a pedestrian crossing [due to the] more and more people who want to cross here to reach the new shops."

The detection of an incident is based on tangible characteristics identified in the environment and how an individual interprets them in the respective location. The perception of an individual of the nature of an incident appears to have an impact on its level of involvement in the reporting process, it also influences the time and number of operations a user is willing to spend and to perform an incident report:

- Interviewer: "According to the severity, you would allow yourself more time for reporting the incident?"

- P15: "Yes that's it!"

Participants differentiate incidents with different degrees of severity ranging from a minor incident to dangerous incidents. The report of a minor incident will generally be driven by the perception that it is citizen duty. In this case, people want to spend very little time, with only some actions to be performed on the smart phone and an interaction time span of less than a minute as, for example:

P16: "As [this is] an incident of little importance, I want something fast, a few steps. It's just a matter of service to the city, to be a good citizen."

Conversely, participants would be willing to spend more time for potentially dangerous incidents, as stated below:

P18: "Because for all minor incidents that is OK to be vague. But there is a need to be accurate [in the case of a dangerous incident] even if it takes more time."

The level of inconvenience is characterized by the troubling nature of the incident either from an organizational point of view or in terms of moral or material values. Inconvenient incident may damage equipment or disturb the peace, as illustrated below:

P16: "The tag generally does not shock me but some content of tags may be disturbing and inappropriate. In this case it should be possible to associate a level of inconvenience to the incident report."

The level of involvement in the incident: Individuals involved in an incident often want to report it and, in such cases, they would devote more time to make a precise report:

- P15: "Here I can take 2 to 3 minutes to write this kind of incident report. It bothers me much less (as reporting a minor incident). Because it affects me directly."

- P16: "If the tag is on my house then it is clear that I will make the report with everything necessary. It all depends on how I am personally involved [with the tag]."

Results for Research Question 2 What dimensions of UX are important for reporting an incident with a mobile-phone application?

To investigate which dimensions of UX are important for reporting an incident with a mobile-phone application (RQ2), the transcripts of the two interviews were analyzed following the Grounded Theory Approach classifying users' statements. The two interviews provided evidence for identifying the following UX dimensions: visual and aesthetic experience, emotion, stimulation, identification, meaning and value, and social relatedness/coexperience. Table III shows how many users mentioned the respective UX dimensions during the interviews and the main findings. This shows the number of participants who provided segments related to the UX dimensions, respectively, during the requirement interviews and during the scenario-based interview. The last column in Table IV shows a synthesis of implications for the user interface design of incident reporting systems. Hereafter, we provide excerpts of participants' comments that illustrate how these UX dimensions are related to incident reporting systems.

In general, visual and aesthetics experience was considered by participants to be less important than other UX dimensions. Nonetheless, interviews point out two interesting aspects: first, the visual quality of a smart-phone application should be better than the visual quality of websites displayed on a smart phone. The second aspect is related to the quality of the pictures taken with smart phones. People want to provide a good and clear picture of the incident and perceive that aspect as important to establish a trustful relationship with the local government. This aspect creates a link between visual and aesthetic experience and the overall trust on the e-government service, as mentioned by:

P15: "If the photo is good, they [the local administration] will see the problem..." 
The interviews identified positive and negative emotions that are related to how people perceive places and their environment (place identity) and to the various levels of the domestic environment (micro/macro level). Emotions were also judged as important to design for, since the application can be a mean to overcome negative experiences, and the reporting of an incident affects users not only in terms of positive emotions (joy), but also influences long-term perceptions (pride). Thus, three sources of emotion have been identified: emotions related to the quality of user environment, negative emotions associated with the occurrence of incidents, and (positive) emotions that can be attributed to the use of the system.

Some participants expressed their pleasure to be in a "high quality" environment; as incident reporting helps to improve the quality of the environment. It also contributes to an overall positive emotional state. For example, some participants think that the application could allow them to experience positive emotions of pride and enthusiasm, especially from having had the opportunity to contribute to the improvement of the environmental quality of the city, as mentioned:

P18: “... I would be very happy to do that [to report of a broken bench]. So the national pride of Toulouse is increased."

Negative emotions are reported from previous experiences especially if an incident directly involves the user (such as a bad experience with a pothole while riding a bicycle). Negative emotions were also related to the degree of influence participants perceive on ability to influence the macro level of the domestic environment, like the perception of overpopulation due to a large number of new buildings in the area, or the increasing level of noise due to heavy traffic. There are some positive emotions can be attributed to the use of a system, in particular, when the system helps users to overcome a negative experience. For example, participants mentioned that the application could help them overcome the (negative) emotional perception and, eventually rationalize the experience, if they are allowed to express themselves via the incident reporting system. Nevertheless, these emotions can be influenced by the users' ability to use the application, as quoted below:

P13: "...under the influence of anger, there is a chance that I miss to report the required data and that as a result the reporting [an incident] is not considered. So they [the system] should use a text field to require users to think a little and calm down..."

Negative emotions also result from fear that an incident report might lead to a reprisal. In the example below, P3 was afraid to take a picture of graffiti leading to the identification of its maker who would felt accused by the incident declaration and then decide to take revenge on the declarant.

Interviewer: "So the problem is to take pictures, so if you make a picture you are afraid that there will be a kind of retaliation?"

$$
\text { P3: "Yes, I got this..., this kind of feeling. Yes." }
$$

The next UX dimension explored is stimulation, which refers to the ability to stimulate users to use the application, for example by recommending the use of specific services. Participants often mentioned that if they were allowed to see incident reports provided by other citizens, they would feel stimulated to look for similar problems in their neighborhood, especially if these incidents involve ideas for improving the quality of life in their neighborhood, for example:

- P4: “... I even find it difficult to imagine that the incident] unless someone talks to me about it. Perhaps the application could prompt us to look at some incidents or perhaps we could see what others have reported and [to incidents that] I am not sensitive to [perceive them]..."

- P7: "Besides going to report your [own] idea, you could ask if there are other ideas [proposed by other]... [that are] close to your home."

Being able to report incidents with a smart phone can be an incentive to be an active member of the (local) community and, thus, start a relationship with the local administration.

P2: “... Having this application [such as an incident reporting system] may give the consciousness of a kind of mission, of vigilance. So one can say that one would not miss any incident, this may encourage people to go out for a walk, instead of staying at home..."

It is noteworthy that this dimension is also related to the perception of vigilance that can involve the security in the neighborhood, which can be considered beyond the scope of incident reporting systems addressed in this work.

The interviews showed that identification is related to three concepts: the identity and personality of the individual, how people identify themselves with 
a place, and the identification with (and attachment to) the smart phone.

Identification is important in all phases of the incident reporting including: people's identification with a place (place identity) supports the diagnosis of the incident (sensitivity to the types of incidents), people's willingness to report an incident (personal values, attachment to places), and identification with the means available for reporting incidents (such as identification with the smart phone).

The identification (identity/personality) therefore concerns all personal values of the user. But identification is also related to the user's interest and ideas, the willingness to act, and to perform citizen duties, for example:

P3: “... Well, maybe my perceptions are a bit unusual compared to others, but I see lots of things to report ... It's in my nature, I am open, and so I'm reporting back information [to the local authorities]. That's it".

Place identity is central to the willingness to report an incident as expressed in:

P14: "Well if it's a bench on which I used to sit with my family every Saturday afternoon... then yes ... it will make it [the intention to report an incident] stronger. But if I just passed by and I never use it, well I do not even know if I would see that it is broken find out."

The level of identification with the smart phone is a positive promoter for incident reporting, for example:

P11: "Usually I cannot forget the appointment with the bulky waste, because I note everything on the agenda of my smart phone that I have always with me."

The value of the incident reporting is influenced by the perception that users have about the utility of their incident reports. The value of incident reporting systems can be reduced if is misused to denunciate someone or to transfer the work from an administrative agent to citizens. For example:

- P1: "Well, it must be of good citizenship anyway. This is the civic duty, it is not denunciation. And the service must works in this spirit".

- P16: "Yes then it does not have the exact location of the pothole, but... it is agent's duties to be careful to locate it [the incident] it in the field. Otherwise I will feel be doing the agents' job, which completely devaluate the service."
The dimension of meaning and value is also directly influenced by the perceived efficiency of the local administration/government. If an incident is reported but never solved, participants are told they would be keen to abandon the application, as stated below:

P12: "On this type of incident I would like information from the back-end service. How they tackle the problem? Are they going to fix it? And at least, if they have understood it [the incident report]? Otherwise it will give the impression that it is useless to make reports and then I'll stop making it."

In general terms, participants think incident reporting systems as worthy in three situations: (a) to provide reliable evidence of existing incidents; (b) to provide personal identification, as evidence of the individual commitment; and (c) to rely on users reporting the same incident. For example:

- P14: (a) "For this incident I want to take a photo as a proof. In this way they can trust me."

- P4: (b) "If we do not identify ourselves, everyone will begin to send anything and everything. Because there are always idiots who play around and misuse applications. So the service loses its value if invaded by spam."

- P17: (c) "I see an interest in knowing that other people reported the incident, like that according the type of incident, I will make an additional incident report to give more importance to the incident, to be sure the incident will be considered by the service."

What became evident in the interviews is that participants did not perceive the incident report as part of their duties; but they felt it more like an act of sharing information. It is like a tweet (twitter message) that helps them to get in touch with the local administration.

In this sense, from the perspective of users, we have to consider the m-government service of incident reporting as a special type of social network. This is clear in the example below where a participant identifies the system UBILOOP as that social network:

- P11: "I take a picture of the broken bench. Then I press the "Share" button. In the smartphone a bunch of social networks is shown where I can put the photo. So there I simply diffuse the photo on the community network UBILOOP." 
TABLE IV

Three Scenarios EXTRACTED From the TASK MOdELS FOR REPORTING AN INCIDENT

\begin{tabular}{|c|c|c|}
\hline Scenario 1: Minimalist report & $\begin{array}{l}\text { Scenario 2: Fair report with } \\
\text { feedback }\end{array}$ & $\begin{array}{l}\text { Scenario 3: Detailed report with pictures } \\
\text { and GPS coordinates }\end{array}$ \\
\hline $\begin{array}{l}\text { detect incident } \\
\text { recognize an incident } \\
\text { identify who should solve the incident } \\
\text { decide to report the incident } \\
\text { submit an incident report } \\
\text { describe the incident } \\
\text { provide textual description } \\
\text { locate the incident } \\
\text { use landmarks } \\
\text { send report }\end{array}$ & $\begin{array}{l}\text { detect incident } \\
\text { recognize an incident } \\
\text { identify who should solve the } \\
\text { incident } \\
\text { decide to report the incident } \\
\text { submit an incident report } \\
\text { describe the incident } \\
\text { select incident category } \\
\text { rate incident } \\
\text { rate potential danger } \\
\text { rate inconvenience } \\
\text { provide a description } \\
\text { provide textual description } \\
\text { locate the incident } \\
\text { provide an address } \\
\text { provide user identification } \\
\text { provide personal coordinates } \\
\text { inform time for the incident } \\
\text { record when the incident is reported } \\
\text { send report } \\
\text { follow up an incident report } \\
\text { subscribe for notification }\end{array}$ & $\begin{array}{l}\text { detect incident } \\
\text { recognize an incident } \\
\text { identify who should solve the incident } \\
\text { decide to report the incident } \\
\text { submit an incident report } \\
\text { describe the incident } \\
\text { select incident category } \\
\text { rate incident } \\
\text { rate potential danger } \\
\text { rate inconvenience } \\
\text { provide a description } \\
\text { provide textual description } \\
\text { provide a picture } \\
\text { provide a picture } \\
\text { provide a picture } \\
\text { locate the incident } \\
\text { solve GPS coordinates } \\
\text { inform time for incident } \\
\text { tell when the incident occurs } \\
\text { send report }\end{array}$ \\
\hline
\end{tabular}

- P13: "I do not care that my report is on track, it's secondary. I want a human being answer me, so I can make sure he understood my problem and that it will be repaired or not. It should not be something automatic; it has to be people who respond."

The participants also express the need for sharing information with other citizens. For example:

P11: "I guess this will be more or less a community network. So I would probably not be alone in reporting the incident."

Results for Research Question 3 What other (contextual) factors are important from a user's point of view when declaring incidents?

The first dimension explored is communication style, which mainly refers to types of synchronous communication (such as via phone call) versus asynchronous communication (such as a text message). In general, the user preference is directed toward an incident report via asynchronous communication. However, the choice of asynchronous communication is not exclusive; some participants redirect their preferences to asynchronous communication (such as making a phone call) to report a dangerous incident or to prevent one (such as removing bulky or garden waste).

P13: “... for this incident, I would like something synchronous.... One solution would be that I send a photo with the GPS and that would allow me to exchange directly on the phone with an agent who could see what I mean by looking at the photo with the incident".

In terms of feedback from the local administration/authorities, participants referred to a notification by email, short text messages (SMS), or a history function within the application, showing which incidents have been reported, and which of these has been successfully removed.

The next dimension explored, diversity of technical platforms, refers to the idiosyncrasies of interaction techniques and the platforms (such as web, Android, or iPhone). Participants referred to the technical possibilities provided by embedded technology into smart phones when describing scenarios, for example:

- P12: “... [for this incident I would use] an audio message rather than text, it would suit me better";

- P19: “... it is sufficient that I activate a vocal command to the GPS system, then it records my position and makes me a memo to report the incident later when I am not driving the car";

The use of incident reporting systems and an internet application accessible from home were mentioned several times, for example:

P1: “... on the Internet at home we could see the diversity of types of incidents reported; this could allow me to think of problems I never thought of before". 


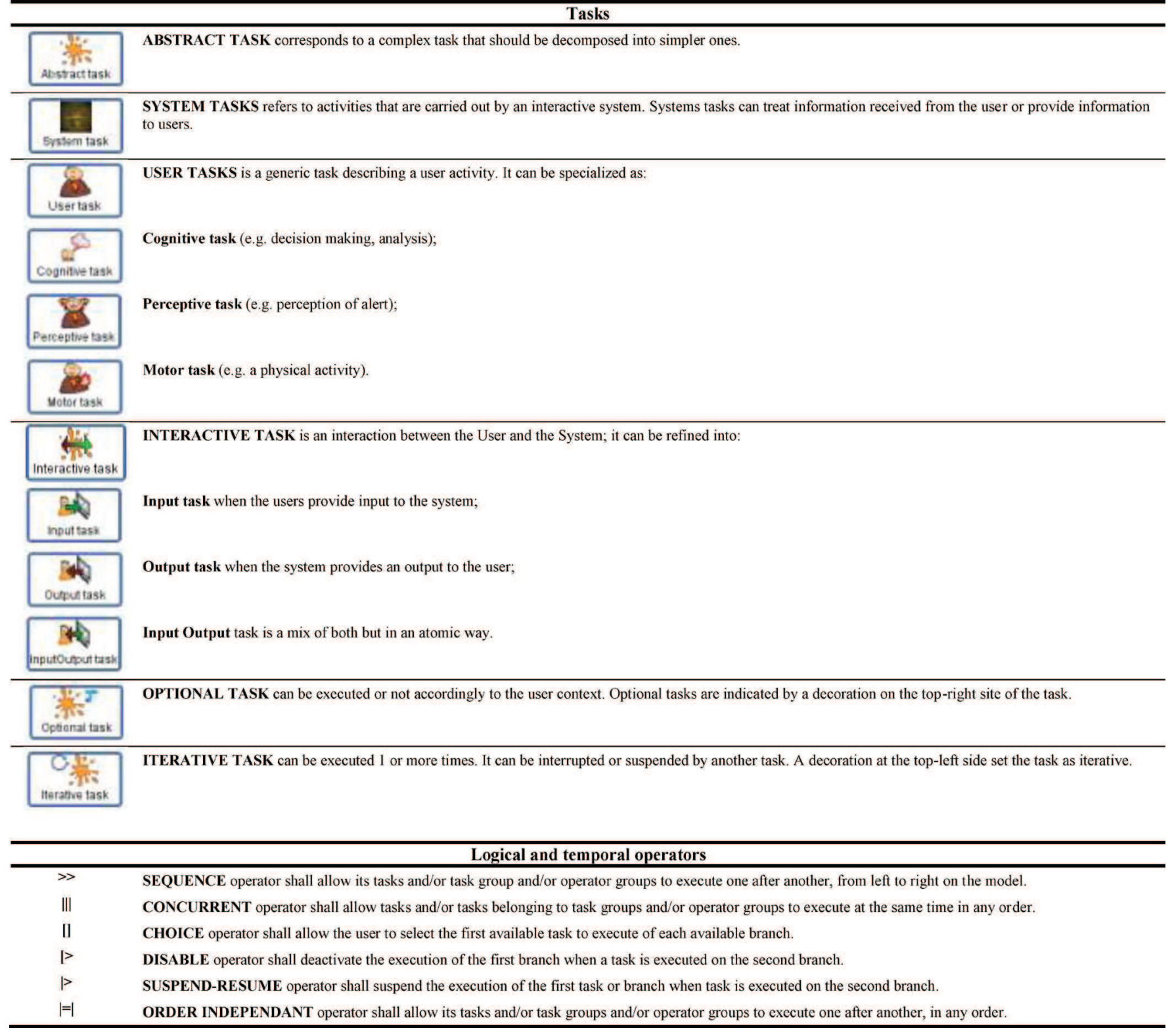

Fig. 2. Tasks and operators in HAMSTER notation.

Most frequently, participants mentioned an application for the smart phone, the ability to send photos of an incident, to send GPS or Cartesian coordinates, to record noise or record voice messages, to use vocal commands, to write text, annotate an image (drawing tool), to access an electronic calendar, to make a video, to select from an interface that simply provides check boxes and form-fill in or text fields, to send an email, to indicate incidents on an interactive map, or to use a personal information system.

Results for Research Question 4 Which of the UX dimensions and contextual factors is important when in the various phases during an incident declaration?

This subsection provides the responses.

To answer this research question, we first need a general task model that is able to describe all of the subtasks that would be possible and necessary to declare an incident. The following section describes the model-based task analysis that was performed to generate such a general task model.

In this subsection, we present a generic task model for incident reporting systems. For that purpose, we employ a task model notation called Human-Centered Assessment and Modeling to 
Support Task Engineering for Resilient Systems (HAMSTERS) [47], which extends model-based approaches, such as CTTE [49], to provide more powerful structuring mechanisms. (See [50] for further details.) The main goal of this model-based task analysis is to describe all possible scenarios, leading users to successfully report an incident to the local administration.

Task models using HAMSTERS are created by identifying the main goal for every user or system activity. Each goal will feature a task in the model that is depicted according to the actors involved in the task execution (such as the user, the system, or both at a time). Complex goals, represented by abstract tasks, are then decomposed in a hierarchy of subtasks. The next step consists in connecting tasks using logical and temporal operators for expressing dependence between task execution (for example, sequence, choice, order independence...). The operators can be used to simulate the execution of tasks; each sequence of execution is then considered a valid scenario to the task model. By using these basic components of the HAMSTER notation shown in Fig. 2, it is possible to create a generic model of user activity with a system.

Task models were created as a generalization of the scenarios previously identified in the study. By analyzing users' scenarios and existing applications, we have found a pattern that encompasses three main tasks: (1) to detect the incident, (2) to submit an incident report, and (3) to follow up on an incident report. Fig. 3 illustrates the hierarchical organization of these tasks using the HAMSTER notation. The operator $\gg$ indicates that these tasks should be performed in sequence. The execution of the tasks starts with "detect incident," continues with "submit an incident report," and finishes with "follow up an incident report." The task "submit an incident" is set as an iterative (symbol on the left-hand side) to indicate that users might revise reports many times before submitting them. The follow up of an incident report is set as optional (see right-hand side symbol) since not all citizens will be interested in the outcomes of an incident report.

The tasks presented in Fig. 3 are complex so they are depicted by abstract tasks. This model has been in the sequence extended as shown in Fig. 4 to accommodate all of the possible variations according to the identified scenarios. For the task "detect incident," we found out that it encompasses the subtasks "recognize an incident" and "identify who should solve an incident and decide to

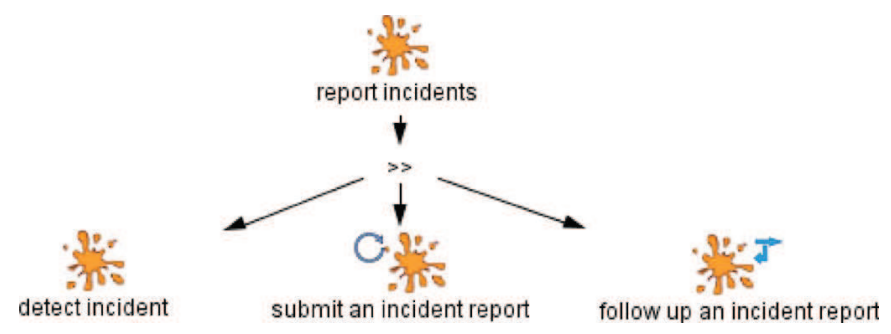

Fig. 3. Main tasks for reporting an incident.

report the incident". The subtask "submit an incident report" encompasses several subtasks for describing an incident report. Generally speaking, the information requested in the identification of the incident includes a description, a location, the time associated with the occurrence of the incident, and the identification of the person reporting the incident. Not all of this information is mandatory for identifying an incident; however, the models indicates that at least the description and the location of the incident should be provided by the user. This means that subtasks "describe an incident" and "locate the incident" are set as mandatory while the subtasks "tell when the incident occurs" and "provide user identification" are described as optional ones. Since the task "submit an incident report" is defined as iterative, all subtasks in this hierarchy can be edited and revised by the user until the subtask "send report is performed." Users can cancel the submission at any time (which is indicated by the operator disabling: $[>)$.

Users can describe an incident in several ways: for example, they can inform the incident category (such as a broken lamp or pothole), rate incident severity, or provide a description for it. Alternatives for such descriptions include sending a text, picture or video, and to call a hot line. The operator $|=|$ indicates that these activities can be done in any order.

The location of an incident is mandatory; otherwise, it would be very difficult to put the means in place to fix it. However, according to the context, the location can be informed as an address, a position on a map, a relative reference to a landmark (for example, in front of the Eiffel tower), or precise GPS coordinates.

A report can be completed by adding optional information about the time and the user. In some situations, users are able to report the time for the incident, which implies the user task "tell when the incident occurred" and the system task "record 
when the incident is reported". The subtask "report time for the incident" is optional because it is very likely that incidents occur without any witnesses so that the exact time of an incident is unknown.

Users might be requested to provide personal identification either by identifying themselves or allowing the system to use personal coordinates already known by the system (for example, a cell-phone number). The level of identification of users can vary considerably from a system to another (for example, from anonymous to providing the user's name, personal address, cell-phone number, and user id). Precise user identification might help the city administration in many ways, for example, to prevent spam and false reporting and to contact the citizen when further information is needed. However, we shall notice that this is a requirement for the administration, not for the users. Indeed, incidents description might remain accurate and valid even if reported anonymously. For all of these reasons, user identification is described as optional.

After submitting a report, some users might want to follow up on an incident report. To allow this, the users should subscribe for notification; otherwise, the current legislation will not authorize the city administration to notify the user directly when the problem will be fixed. It is worth noting that the subscription for notification might also engage users in communication with the city administration. Some users might want to share reports using a social network or just be interested in seeing reports sent by others users. Of course, not all users will follow up on an incident report so closely, so this and all subsequent subtasks are described as optional.

The task model presented in Fig. 4 provides a comprehensive view of tasks related to incident reporting; however, it does not impose any particular design for the system. Indeed, many sequences of tasks performed on that task model lead to different suitable scenarios to reach the same goal. Using the simulator embedded into the HAMSTER editor, it is possible to extract all scenarios supported by a task model. Table IV illustrates only three possible scenarios extracted from the task model for incident reporting.

Scenario 1, presented by Table IV, will require a very minimalist system featuring a few text fields where users can provide textual description; locate the incident using landmarks and a button to send the report. Scenario 2 requires more information from users and, as a consequence, a more complex user interface, as users should select incident category, rate the incident (both danger and inconvenience), provide a textual description of the incident, provide an address, and provide personal coordinates which will ultimately be required when the users ask to subscribe for notification. Scenario 3 will ultimately require a far more complex user interface not only to accommodate the tasks described in scenario 2 but also to integrate tasks, allowing users to provide pictures of the incident and allowing the system to solve GPS coordinates that will be automatically added as part of the incident report.

The task model is considered valid as we can accommodate all of the scenarios identified during interviews and/or supported by the systems assessed in the survey.

Developing a Task Model From the Results The mapping between the task model and existing systems has been shown in Table II.

Based on the association of UX dimensions with tasks via the interpolation of user scenarios, it was possible to extrapolate the results in a single task model as shown in Fig. 5. In order to illustrate how Fig. 5 should be read, let us consider a simple scenario: "A citizen sees a broken bench in a park and then decides to make an incident report. His motivation for reporting is to take actively part in the community. As the incident is of some importance to him, there is a variety of detailed information given in the report, including a photo and geo-localization data. Our citizen also wants that the incident report is also available for other users but he prefers to stay anonymous when using the application". The task model presented by Fig. 5 supports this scenario. It is worth noting that this model has been decorated with rectangles that represent different UX dimensions (such as [AX] for visual experience, [ID] for identification). These decorations aim at highlighting where, during the task executions, UX dimensions were found to be important by interviewing participants. The importance is derived from the frequency of UX dimensions in the user's scenarios as shown in Table III. In order to illustrate how the task model presented by Fig. 5 should be read, we provide hereafter an extended scenario including UX dimensions:

"I am passing by at this park every Sunday and this bench has not been repaired for weeks

[ID]. It is time now to report that, so it will get fixed. It is not really a problem or unsafe, but the bench is simply not usable in the current 


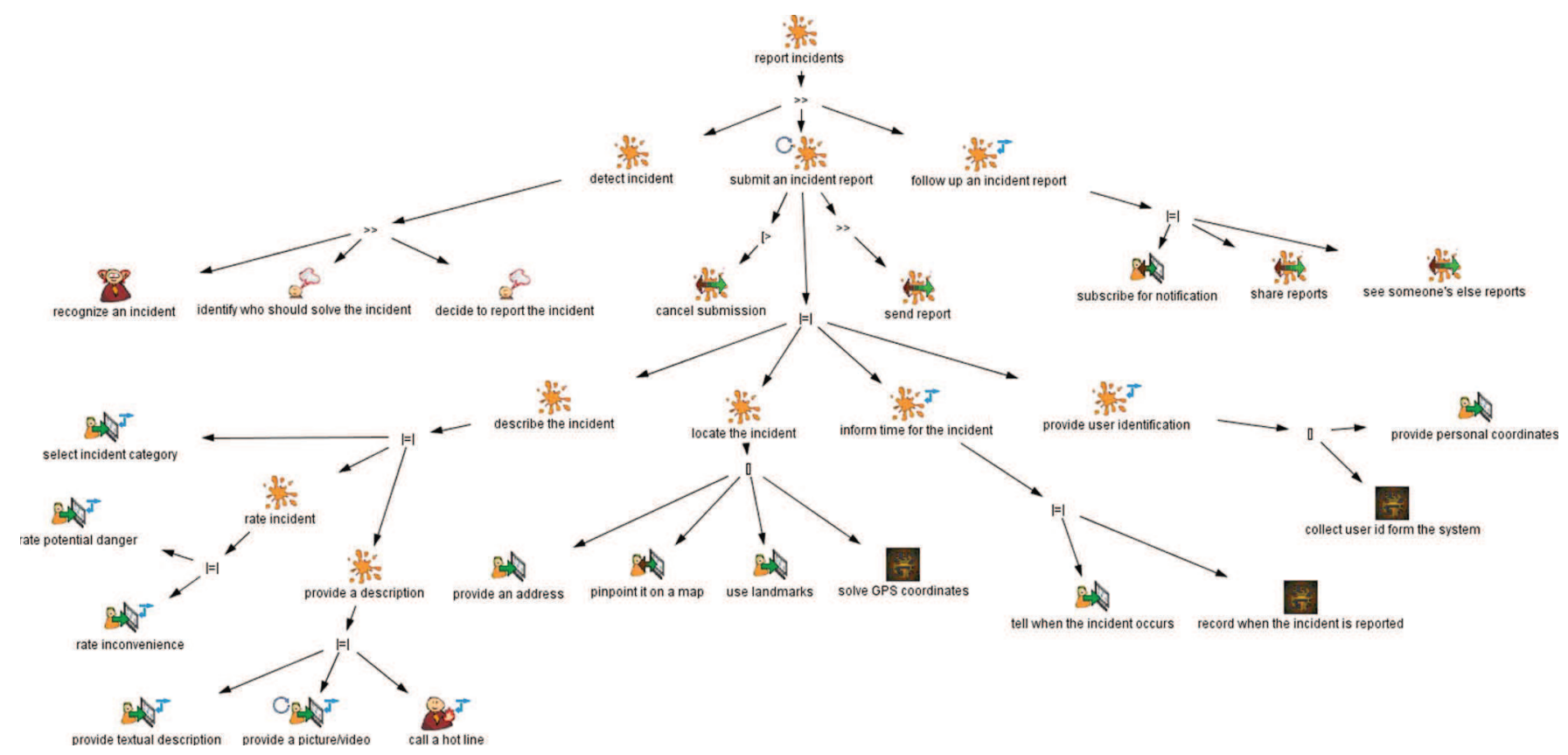

Fig. 4. Generic task model for reporting an incident.

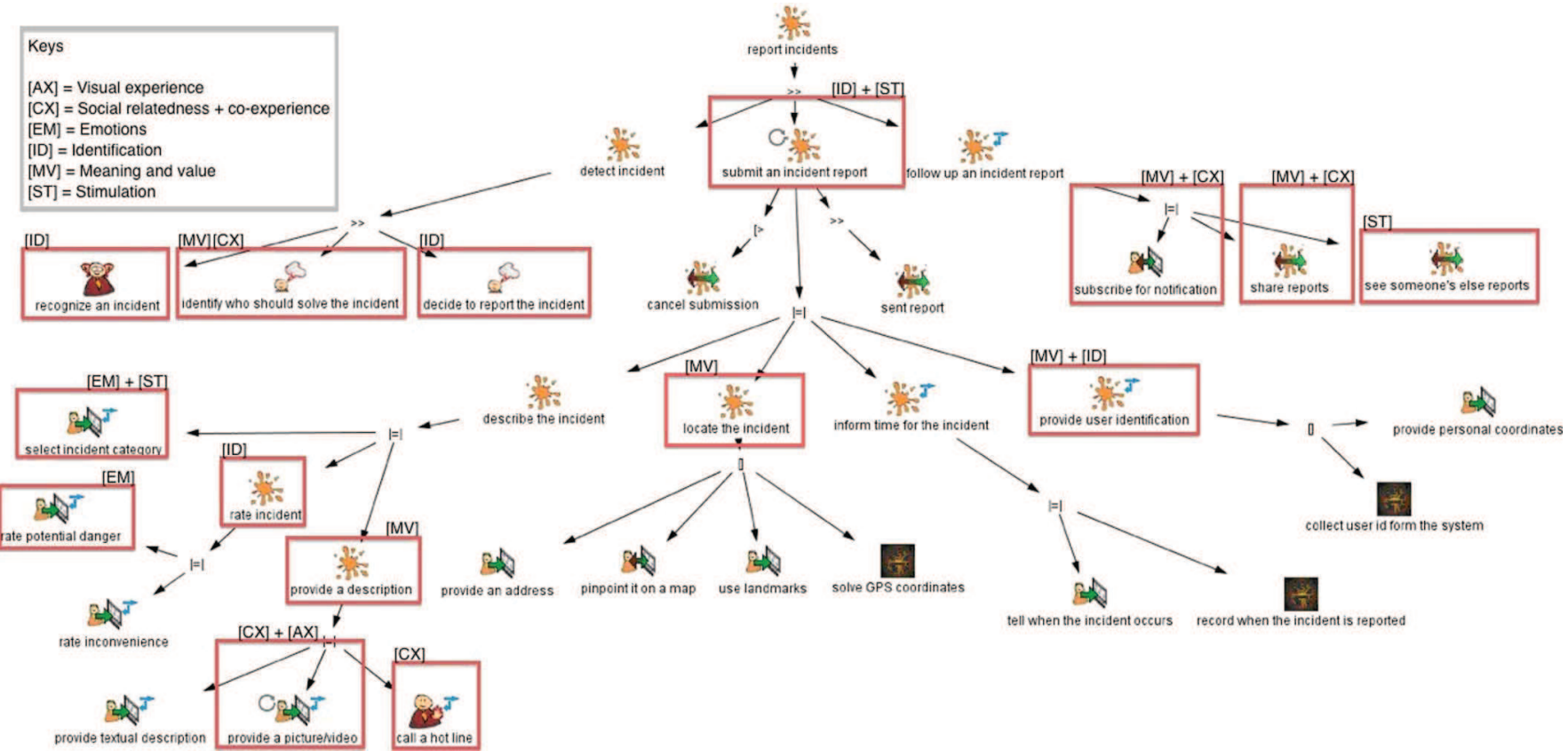

Fig. 5. Generic task and most important UX dimensions for each subtask.

state [MV]. [:detect/recognize the incident:]. It seems important now to make sure that the appropriate person is informed about that bench [CX], I think I should use the application to report the incident, because I want to be a good citizen [ID]. I think it is a good idea to send them a photo so they can see that the bench is really broken and that the wood has to be replaced. And when they see the photo they see that it is really there and so they will not need my contact information to have a proof that the broken bench really exists. [MV] [:describe the incident:]. (and so on)".

This example shows how user tasks are interrelated to the UX dimensions. The various UX dimensions 
do apply to the subtasks to a varying degree. We just refer to the most important UX dimensions in the diagram. There is one subtask that is not related to any UX dimension because it is optional and it is considered as an automatic task (by the system), such as [: inform time for the incident:]. All UX dimensions have been associated with the subtasks. It is interesting to notice that some tasks (such as [provide a picture/video]) can be influenced by more than one UX dimension (such as visual experience and aesthetic, and social relatedness coexperience) while other tasks can be considered neutral with respect to UX dimensions; which means that, even if necessary for the system, these tasks do not raise any particular UX. One possible implication for this association is that if designers want to reinforce or create a specific UX dimension, they might work on the tasks that might have an impact on users.

Table III provides a summary of the results collected by combining task models and interviews. Since our main focus was to analyze UX dimensions, the other segments of the corpus are not included in the table. The fourth column shows the total number of segments (in both interviews). About $45 \%$ of the interviews corpus talks about the overall UX dimensions (506 segments/1125). The fifth column shows the mapping of UX dimensions and user tasks.

It is interesting to notice that the UX dimensions identification (29.6\%), mean and value (21.7\%), and social relatedness/coexperience (26.7\%) were frequent in all interviews. Except for emotions and stimulation, we could not find any difference between the numbers of participants reporting segments allowing the identification of $U X$ dimensions. In the case of emotions, it was referred by all participants of the requirement interviews, while only $2 / 3$ ( $N=6$ out 9$)$ of participants of the scenario-based interview mention this dimension. The case of stimulation is more contrasting as only two participants mention this dimension during the scenario-based interview while all participants mention it during the requirement interview. This difference can be explained by the counting method since we only consider new scenarios provided by the participants themselves; the fact that the scenario-based interview prompted participants to focus on specific scenarios might have prevented them to talk spontaneously about new scenarios.

\section{CONCLUSIONS, Limitations, AND SUggestions FOR FUTURE RESEARCH}

This section concludes this paper. It aims at summarizing the main conclusions of our study, identifies its limitations, and discusses the implications for future research.

Conclusions This paper provided two main kinds of contributions that are worth discussing: the first one refers to the knowledge that can be obtained in terms of UX dimensions affecting self-services for reporting incidents; the second refers to the methodological aspects involving the triangulation of methods, which might provide some insight into associate UX dimensions and user interface design. Hereafter, we present our conclusions followed by limitations and future research.

A significant result from the present study is to point out the effect of UX dimensions in the task engaged by users. The semidirected requirement interviews showed several social implications for the task of reporting incidents in an urban context. These social implications can be translated by several UX dimensions, such as emotions (that motivate users to report an incident), user identification (tells which particular incidents users are willing to spend some time for writing a report), and visual experience (how aesthetics affect user perception of the system) that might influence the act of reporting an incident. However, the results show that the importance of UX dimensions is not equally distributed along the several subtasks that citizens engage in when reporting incidents. By using a model-based task analysis, it was possible to remove ambiguities present in the discourse of participants and then to formalize users' requirements. Moreover, model-based task analysis provided an accurate description of user tasks. As described in [47] and [50], tasks models not only improve the understanding of user tasks but they also can be used to assess whether an incident reporting system was effectively implemented to support the specified set of user tasks.

The second element for discussion is on the choice of methods. To identify UX dimensions that are important in the area of incident reporting, a triangulated method approach was chosen by combining a model-based task analysis, a survey of existing systems, and a set of requirement interviews. Model-based task analysis was chosen to provide a common ground for comparing incident reporting systems worldwide. The task model was also demonstrated as useful to anchor the findings expressed by users during semidirected 
requirement interviews in terms of: users' scenarios that correspond to the general task model, and UX dimensions that are always reported in connection with tasks. Task models were thus used as a kind of "lingua franca," enabling us to identify a set of UX dimensions and their relation to (sub) tasks of incident reporting.

By combining these methods, it was possible to provide a clear representation of the tasks and to point out the lack of support for existing applications. This aspect of the present research will certainly help designers understand which tasks are worthy of more attention in order to produce the expected UX result. Conversely, designers can focus on specific UX dimensions and look up the tasks that users are more likely to perceive as desired effects. It is worth noting that instead of using a specific application, we investigate a generic tasks model from which several scenarios could be extracted and then analyzed. This step is extremely important for the future development of new incident reporting systems. We suggest that an approach for task analysis is extremely helpful to cover all design options to achieve a given goal.

The knowledge-obtained user requirements from incident reporting systems can be directly employed in the design of future applications. On one hand, this can be read as a set of recommendations for designing incident reporting systems. (See Table III.) On the other hand, this work has identified how UX dimensions affect tasks for incident reporting systems. So if governmental agencies want to provide high-quality incident reporting systems, they should concentrate their efforts on the design of applications that communicate positive UX dimensions. However, further investigation is necessary to determine whether (or not) users' perception of UX dimensions can influence the design of such systems in other countries.

As far as the use of methods is concerned, the proposed triangulation of methods might provide new insights for interpreting results related to overall UX and how to plot them into tasks models, which are aimed to support design activities. The mapping among methods was possible because it is easy to identify the concept of tasks in scenarios reported by users and to identify tasks behind the functions provided by existing systems. Despite this being a first attempt, we assume that approach can be reused in other studies related to UX and user interface design.
The investigation of incident reporting systems in the e-government domain is quite new. Despite the fact that many applications exist, we could not find any detailed analysis about the user tasks for declaring incidents. The lack of detailed analysis of user tasks can explain, at least partly, problems such as late adoption and definite rejection of applications. The discussion presented on UX presented in this paper might be considered useful for pointing out where to look at for overall user experience with e/m-government applications. We expect that these results could contribute to further research in the field and contribute to build a more general understanding about how UX dimensions affect users of e/m-government applications.

Limitations Our results are based on the citizens' point of view and, thus, only provide insights on UX dimensions that users felt were important. Indeed, the study does not taken into account the point of view of stakeholders who might have different criteria for assessing the importance of tasks. Another limitation is that the study was held in early phases of the development process. The UX dimensions identified are thus associated with requirements that are derived from citizens' expectations and previous experiences, as reported during the interviews. An additional investigation should be conducted to establish a correlation between UX dimensions identified in early phases of the development process and those dimensions that can be observed after system deployment and usage of applications. Another limitation to the interpretation of UX dimensions is from the transcripts of the interviews. Indeed, the coding of UX dimensions was based on expert reviews that are aimed to interpret the findings according to a predefined set of dimensions. Nevertheless, two measures have been taken to reduce the impact of subjectivity of interpretations: first of all, clear definitions of UX dimensions were defined before starting the coding, thus providing a scope for interpreting the segments; then, the coding was revised by independent experts, who conducted cross-checking, so that the coding provided makes sense.

Some of the results might provide insights about how users perceive their environment, their willingness to report incidents to authorities, and how UX dimensions are related to user tasks, which might influence the design of tools for improving the communications with administration. However, the interpretation of results is limited to the context of e/m-government applications. Moreover, it is limited by the cultural context in France where the 
study was run. It is noteworthy that even if the identification of UX dimensions is valid for incident reporting system, in general, the detailed results are very specific to the e-government domain since we have to focus on citizens and the quality of their environment. Further studies will be required to investigate whether the results might remain valid for other kinds of applications.

Suggestions for Future Research Further studies will be required to take into account requirements raised by administrative agencies and deputies. Our next steps within the project thus include:

- The design and implementation of incident reporting system for mobile phones. Currently, we are designing an application based on a user-centered design approach that integrates the UX dimensions identified in this paper. Our aim is to deploy our application in several mobile platforms so that we can pursue our research toward the investigation of how specific features of mobile platform might affect the UX of systems for reporting incidents.

- A user testing experiment with end users is going to organize to assess the usability and the UX of the prototypes. Our main goal is to compare the results of actual use of running prototypes with the UX dimensions identified in the interviews.

- The availability of these prototypes also opens the perspective for establishing longitudinal studies on the evolution of the UX. After having tested the initial prototypes and having fixed the major usability and UX flaws that might be introduced during the development process, we aim to deploy the applications to a larger population to collect data about their experiences with the systems. Such a strategy allows the comparison of UX dimensions expressed as user requirements (the present study), user experience in the initial use, and user experience over 6 months using the system.

The Ubiloop project has focused on incident reporting in an urban context of use. However, as discussed in the introduction of this paper, incident reporting systems are relevant to a broader range of application domains. Despite the fact that we focus on incident reporting as an e-government service, some of our results can also be extended (in particular, when looking at geolocalization and temporal issues) to other domains, such as air-traffic management and health. Over the long term, we would like to investigate in which extension the UX dimensions identified in the present study remain relevant if the application domain changes. The investigation of influences of the domain can be held because the overall tasks remain the same. This issue is beyond of the scope defined for the Ubiloop project but the tasks and the inner context can provide an initial framework to address such scientific questions.

\section{ACKNOWLEDGMENTS}

This work is part of the Ubiloop project partly funded by the European Union. Europe is moving in France Midi-Pyrenees with the European Regional Development Fund (ERDF).

\section{REFERENCES}

[1] C. W. Johnson, Failure in Safety-Critical Systems: A Handbook of Accident and Incident Reporting. Glasgow, UK: University of Glasgow Press, 2003.

[2] J. T. Reason, "Human error: Models and management," Brit. Med. J., 2000.

[3] M. Kaufmann, S. Staender, G. von Below, H. Brunnerc, L. Portenier, and D. Scheidegger, "Déclaration anonyme informatisée d'incidents critiques: Une contribution à la sécurité des patients," Bull. Médecins Suisses, vol. 84, 2003.

[4] M. Winckler, R. Bernhaupt, and F. Pontico, "Challenges for the development of user interface pattern languages: A case study on the e-government domain," IADIS Int.J. WWW/Internet, vol. 8, no. 2, pp. 59-84, 2010.

[5] T. El Kiki and E. Lawrence, "Mobile user satisfaction and usage analysis model of mgovernment services," presented at the 2nd Eur. Conf. Mobile Gov., Brighton, UK, 2006.

[6] G. Song, "Transcending e-Government: A case of mobile government in Beijing," presented at the 1st Eur. Conf. Mobile Gov., Sussex, UK, Jul. 2005.

[7] J. Moon, IBM Center for the Business of Government. (2004). From e-Government? Emerging practices in the use of M-Technology by state governments. [Online]. Available: http://www.businessofgovernment.org/ report/e-government-m-government-emerging-practices-use-mobile-technology-state-governments

[8] F. Carcillo, L. Marcellin, and A. Tringale, "BlueTo: A location-based service for m-government solutions," in Proc. EURO. mGOV., 2006, pp. 51-60.

[9] M. Ntaliani, C. Costopoulou, N. Manouselis, and S. Karetsos, "M-government services for rural SMEs," Int. J. Electron. Secur. Digit. Forens., vol. 2, no. 4, pp. 407-423, 2009. 
[10] G. Misuraca, "Futuring e-government: Governance and policy implications for designing ICT-enabled knowledge society," presented at the ICEGOV, Bogota, Colombia, 2009.

[11] mySociety Ltd., Fixmystreet. (2012, Jan. 30). [Online]. Available: http://www.fixmystreet.com

[12] P. Rossel, M. Finger, and G. Misuraca, "Mobile e-government options: Between technology-driven and user centric," Electron. J. e-Gov., vol. 4, no. 2, pp. 79-86, 2006.

[13] I. Kushchu and H. Kuscu, "From e-government to m-government: Facing the inevitable," presented at the Eur. Conf. E-Government, Dublin, Ireland, 2003.

[14] M. Winckler, D. L. Scapin, F. Pontico, G. Calvary, and A. Serna, "Profiling user requirements for multi-target e-government applications: A case study," in Proc. Int. Workshop Design Eval. e-Government Appl. Services, Uppsala, Sweden, Aug. 8, 2009, vol. 492, pp. 9-16.

[15] R. Bernhaupt, User Experience Evaluation in Games and Entertainment. Berlin, Germany: Springer-Verlag, 2010.

[16] J. O'Looney, IBM Center for the Business of Government. (2003). Using technology to increase citizen participation in government: The use of models and simulation. [Online]. Available: http://www.businessofgovernment.org/report/using-technology-increase-citizen-participation-governmentuse-models-and-simulation

[17] D. P. Moynihan, IBM Center for the Business of Government. (2007). From forest fires to Hurricane Katrina: Case studies of incident command systems. [Online]. Available: http://www.businessofgovernment.org/ report/forest-fires-hurricane-katrina-case-studies-incident-command-systems

[18] M. L. Meuter, A. L. Ostrom, M. J. Bitner, and R. Roundtree, "The influence of technology anxiety on consumer use and experiences with welf-service technologies," J. Bus. Res., vol. 56, pp. 899-906, 2003.

[19] M. von Wilamowitz-Moellendorff, M. Hassenzahl, and A. Platz, "Dynamics of user experience: How the perceived quality of mobile phones changes over time," in Proc. User Experience-Towards a Unified View, Workshop at the 4th Nordic Conf. Human-Comput. Interact., 2006, pp. 74-78.

[20] E. Law and P. Van Schaik, "Modelling user experience-An agenda for research and practice," Interact. Comput., vol. 22, no. 5, pp. 313-322, 2010.

[21] E. Law, V. Roto, M. Hassenzahl, A. Vermeeren, and J. Kort, "Understanding, scoping and defining user experience: A survey approach," presented at the CHI, Boston, MA, 2009.

[22] E. Law, "The measurability and predictability of user experience," in Proc. EICS, New York, 2011, pp. 1-10.

[23] M. Pirker, R. Bernhaupt, and T. Mirlacher, "Investigating usability and user experience as possible entry barriers for touch interaction in the living room," in Proc. Euroitv, 2010, pp. 145-154.

[24] P. Hekkert, "Design aesthetics: Principles of pleasure in product design," Psychol. Sci., vol. 48, no. 2, pp. 157-172, 2006.

[25] M. Hassenzahl, "The thing and I: Understanding the relationship between user and product," in Funology: From Usability to Enjoyment, M. Blythe, C. Overbeeke, A. F. Monk, and P. C. Wright, Eds. Dordrecht, the Netherlands: Kluwer, 2003, pp. 31-42.

[26] T. Lavie and N. Tractinsky, "Assessing dimensions of perceived visual aesthetics of web sites," Int. J. Human-Comput. Studies, vol. 60, no. 3, pp. 269-298, 2004.

[27] M. Hassenzahl and N. Tractinsky, "User experience-A research agenda," Behav. Inf. Technol., vol. 25, no. 2, pp. 91-97, 2006.

[28] L. Alben, "Quality of experience: Defining the criteria for effective interaction design," Interactions, vol. 3, pp. 11-15, 1996.

[29] J. M. Quinn and T. Q. Tran, "Attractive phones don't have to work better: Independent effects of attractiveness, effectiveness, and efficiency on perceived usability," in Proc. CHI, New York, 2010, pp. 353-362.

[30] P. M. A. Desmet and P. Hekkert, "Framework of product experience," Int. J. Design, vol. 1, no. 1, pp. 57-66, 2007.

[31] S. Mahlke and M. Thüring, "Studying antecedents of emotional experiences in interactive contexts," in Proc. CHI, New York, 2007, pp. 915-918.

[32] K. M. Sheldon, A. J. Elliot, Y. Kim, and T. Kasser, "What is satisfying about satisfying events? Testing 10 candidate psychological needs," J. Personal. Social Psychol., vol. 80, no. 2, pp. 325-339, 2001.

[33] E. Karapanos, J. Zimmerman, J. Forlizzi, and J.-B. Martens, "Measuring the dynamics of remembered experience over time," Interact. Comput., vol. 22, no. 5, pp. 328-335, 2010.

[34] M. Hassenzahl, "Aesthetics in interactive products: Correlates and consequences of beauty," in Product Exper. New York: Elsevier, 2008, ch. 11, pp. 287-302.

[35] V. Jääskö and T. Mattelmäki, "Observing and probing," in Proc. DPPI, New York, 2003, pp. $126-131$.

[36] P. Jordan, Designing Pleasurable Products: An Introduction to the New Human Factors. London, UK: Taylor \& Francis, 2000.

[37] B. Gaver and H. Martin, "Alternatives: Exploring information appliances through conceptual design proposals," in Proc. CHI, New York, 2000, pp. 209-216.

[38] K. Väänänen-Vainio-Mattila, V. Roto, and M. Hassenzahl, "Now let's do it in practice: User experience evaluation methods in product development," in Proc. Extended Abstracts Human Factors Comput. Syst., 2008, pp. 3961-3964.

[39] K. Väänänen-Vainio-Mattila, "Towards a life cycle framework of mobile service user experience," presented at the 2nd MIUX Workshop at MobileHCI, Amsterdam, the Netherlands, 2008. 
[40] K. Väänänen-Vainio-Mattila, H. Väätäjä, and T. Vainio, P. Saariluoma and H. Isomäki, Eds., "Opportunities and chalengers of designing the service user eXperiense (SUX) in Web 2.0," in Future Interaction Design II. New York: Springer, 2008.

[41] W. H. Ittelson, H. M. Procshansky, L. G. Rivlin, and G. H. Winkel, An Introduction to Environmental Psychology. New York: : Holt, Rinehart, and Winston, 1974.

[42] H. Proshansky, A. Fabian, and R. Kaminoff, "Place identity: Physical world socialization of the self," J. Environ. Psychol., pp. 57-83, 1983.

[43] A. Moles and E. Rohmer, Psychologie de l'espace. Strasbourg, France: Casterman, 1978.

[44] J. Lazar, J. H. Feng, and H. Hochheiser, Research Methods in Human-Computer Interaction. Hoboken, NJ: Wiley, 2010.

[45] B. G. Glaser and A. L. Strauss, The Discovery of Grounded Theory: Strategies for Qualitative Research. Chicago, IL: Adline, 1967.

[46] D. Diaper and N. A. Stanton, Eds., The Handbook of Task Analysis for Human-Computer Interaction. Mahwah, NJ: Erlbaum, 2004, p. 650.

[47] E. Barboni, J. Ladry, D. Navarre, P. Palanque, and M. Winckler, "Beyond modelling: An integrated environment supporting co-execution of tasks and systems models," in Proc. 2nd ACM SIGCHI Symp. Eng. Interact. Comput. Syst., New York, Jun. 2010, pp. 165-174.

[48] QDA Software Ltd., MaxQDA, 1995. [Online]. Available: http://www.maxqda.com

[49] M. Giulio, F. Paternò, and C. Santoro, "CTTE: Support for developing and analyzing task models for interactive system design,” IEEE Trans. Software Eng., vol. 28, no. 8, pp. 797-813, Aug. 2002.

[50] C. Martinie, P. A. Palanque, and M. Winckler, "Structuring and composition mechanisms to address scalability issues in task models," in Proc. INTERACT, 2011, vol. 3, pp. 589-609.

Marco Winckler received the Ph.D. degree in Informatics from the University of Toulouse 1 Capitole, France, in 2004. Currently, he is Assistant Professor in Computer Sciences, Université Paul Sabatier, Toulouse, France, and a member of the Interactive Critical System (ICS) research team of the Institute of Research in Informatics of Toulouse (IRIT). His research focuses on models, methods, techniques and tools to support the development of reliable, usable, and effective interactive systems. He serves as Vice-Chair for the IFIP working group 13.2 on Methodologies for User-Centered Systems Design and he is expert member of the IFIP TC 13 on Human-Computer Interaction.

Cedric Bach received the Ph.D. degree from the institute INRIA Rocquencourt, France, in 2004. Currently, he is a full-time researcher at the Ergonomics and Human Factors Department, Bertin Technologies, Toulouse, France. As a Human Factors specialist, he daily analyzes models, and designs and evaluates different types of human-machine interaction. For 10 years, his academic research has focused on the usability engineering in different domains, such as aeronautics, space, mobile technologies, and virtual environments.

Regina Bernhaupt received the Ph.D. degree in applied informatics at the University of Salzburg. She is invited Professor at the University Paul Sabatier/ Institute of Research in Informatics of Toulouse (IRIT). In addition, she is Director of User Experience Research at ruwido research (www.ruwido.com). She is an active member of the community on human-computer interaction, having organized conferences and several workshops. Her work focuses on how to evaluate usability and user experience in various contexts, especially for entertainment-oriented products and services. She recently edited a book on evaluating user experience in games and is the author of several international publications. 